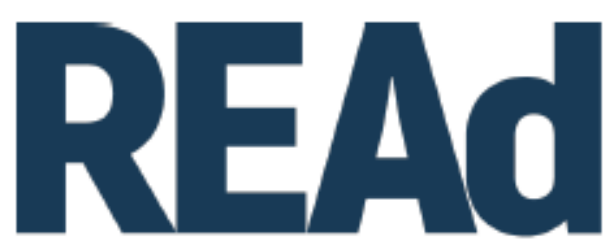

Revista Eletrônica de Administração

\title{
PROPOSTA DE CONSTRUÇÃO DE MODELO DE MATURIDADE EM \\ GOVERNANÇA E GESTÃO DE TIC ${ }^{12}$
}

\author{
Pedro Otávio Londe dos Santos ${ }^{3}$ \\ Ana Paula Bernardi da Silva ${ }^{4}$ \\ João Souza Neto ${ }^{5}$ \\ Rafael Timóteo de Sousa Júnior ${ }^{6}$
}

\section{http://dx.doi.org/10.1590/1413-2311.291.97046}

\begin{abstract}
RESUMO
Trata-se de uma proposta de um modelo de avaliação da maturidade em governança e gestão de Tecnologia da Informação e Comunicação (TIC) para os órgãos da Administração Pública Federal (APF) pertencentes ao Sistema de Administração dos Recursos de Informação e Informática (SISP) do Poder Executivo. Identificou-se os critérios de maturidade da literatura que subsidiaram a aplicação da Teoria Fundamentada para se obter as conceituações sobre governança e gestão de TIC na visão do SISP. De posse desses elementos, elaborou-se o referido modelo para fomentar a melhoria dos níveis de maturidade em governança e gestão de TIC no Governo Federal sob a ótica do SISP. A pesquisa concluiu que a maturidade em governança e gestão de TIC envolve mudanças no desempenho, na cultura organizacional e

\footnotetext{
${ }^{1}$ Recebido em 30/9/2019, aceito em 10/8/2020.

${ }^{2} \mathrm{O}$ presente artigo foi realizado com apoio dos seguintes órgãos/financiamentos: CNPq 312180/2019-

5, BRICS2017-591 e 465741/2014-2; CAPES 23038.007604/2014-69 e 88887.144009/2017-00; FAPDF 0193.001366/2016 e 0193.001365/2016; ME 005/2016 e 083/2016; GSI/PR ABIN 002/2017; CADE 08700.000047/2019-14; AGU 697.935/2019.

${ }^{3}$ Universidade Católica de Brasília - Programa de Pós-Graduação em Governança, Tecnologia e Inovação, Brasília - DF (Brasil); http://orcid.org/0000-0002-3428-1942; pedrolonde@ hotmail.com.

${ }^{4}$ Universidade Católica de Brasília - Programa de Pós-Graduação em Governança, Tecnologia e Inovação, Brasília - DF (Brasil);http://orcid.org/0000-0002-9963-282X; anap.bernardi@ gmail.com.

${ }^{5}$ Universidade Católica de Brasília - Programa de Pós-Graduação em Governança, Tecnologia e Inovação, Brasília - DF (Brasil); http://orcid.org/0000-0002-4853-8788; sznetoj@ gmail.com.

${ }^{6}$ Universidade de Brasília - Programas de Pós-Graduação Acadêmico e Profissional em Engenharia Elétrica, Brasília - DF (Brasil); http://orcid.org/0000-0003-1101-3029; desousa1961@ gmail.com.
} 
nos controles internos. O emprego da Teoria Fundamentada permitiu desenvolver conceitos sobre governança e gestão de TIC baseados nas documentações do SISP com conceituações sem premissas e vieses pessoais.

Palavras-chave: Governança de TIC. Modelo de maturidade. Administração Pública Federal (APF). Brasil.

\section{PROPOSAL TO BUILD A MATURITY MODEL IN ICT GOVERNANCE AND MANAGEMENT}

This is a proposal for a model for evaluating the maturity in governance and management of Information and Communication Technology (ICT) for the Federal Public Administration (APF), belonging to the Information and Information Resource Management System (SISP). of the executive branch. We identified the criteria of literature maturity that supported the application of Grounded Theory to obtain the conceptualizations on governance and ICT management in the SISP view. With these elements in mind, this model was elaborated to foster the improvement of maturity levels in ICT governance and management in the Federal Government as a whole from the perspective of SISP. The research concluded that maturity in ICT governance and management involves changes in performance, organizational culture and internal controls. The use of Grounded Theory allowed the development of concepts on governance and ICT management based on SISP documentation with conceptualizations without premises and personal biases.

Keywords: ICT Governance. Maturity model. ICT Governance in APF.

\section{PROPUESTA DE MODELO DE MADUREZ DE GOBERNANZA Y GESTIÓN DE LAS TIC}

Esta es una propuesta de modelo para evaluar la madurez en la gobernanza y gestión de la Tecnología de la Información y la Comunicación (TIC) para la Administración Pública Federal (APF), perteneciente al Sistema de Gestión de Recursos de Información e Información (SISP). del poder ejecutivo. Identificamos los criterios de madurez de la literatura que respaldaron la aplicación de la teoría fundamentada para obtener las conceptualizaciones sobre la gobernanza y la gestión de las TIC en la vista SISP. Con estos elementos en mente, este modelo se elaboró para fomentar la mejora de los niveles de madurez en la gobernanza y gestión de las TIC en el Gobierno Federal en su conjunto desde la perspectiva del SISP. La investigación concluyó que la madurez en la gobernanza y gestión 
de las TIC implica cambios en el desempeño, la cultura organizacional y los controles internos. El uso de la teoría fundamentada permitió el desarrollo de conceptos sobre gobernanza y gestión de las TIC basados en la documentación del SISP con conceptualizaciones sin premisas y prejuicios personales.

Palabras clave: Gobierno de las TIC. Modelo de madurez. SISP Gobierno de las TIC en APF.

\section{INTRODUÇÃO}

As diretrizes da governança de Tecnologias da Informação e Comunicação (TIC) viabilizam uma utilização efetiva dos recursos de TIC (Wu; Straub; Liang, 2015), o que indica a possibilidade de a governança de TIC viabilizar uma gestão eficaz de TIC no âmbito da Administração Pública Federal (APF) brasileira. Entretanto, por meio de levantamentos realizados nos anos de 2007, 2010, 2012 e 2014, o Tribunal de Contas da União (TCU) pôde constatar que a adoção das boas práticas de governança de TIC na APF ainda se encontra aquém do recomendado (TCU, 2015).

Cabe levar em consideração quanto essa questão as contribuições e as diretrizes do Sistema de Administração dos Recursos de Tecnologia da Informação (SISP) no âmbito do Poder Executivo Federal. Trata-se de um sistema criado em 1994 para gerenciar os recursos de informação sob a normatização do Ministério do Planejamento, Desenvolvimento e Gestão (MPDG, 2011). Em dezembro do ano de 2015, o SISP lançou um guia de implementação da governança de TIC para os órgãos da APF. Além desse guia, o SISP também lançou orientações para Estratégias Gerais de TIC (EGTIC), Planos Diretores de TIC (PDTIC) e Comitês de TIC. Portanto, é relevante aos agentes públicos do Executivo Federal manteremse atualizados com as publicações do TCU e do SISP.

Para induzir melhorias na governança de TIC, o TCU criou um índice de avaliação geral da situação da governança de TIC nas organizações públicas (iGovTI). Reconhece-se que esse índice não é uma medição precisa das capacidades em governança e gestão de TIC dos avaliados visto que o questionário não consegue contemplar todas as variáveis influenciadoras (TCU, 2016). Diante desse contexto, constata-se a necessidade de um modelo para avaliar a maturidade da governança e gestão de TIC na APF, constituindo uma questão que afeta diretamente a execução das políticas governamentais. A proposição de um modelo para responder a tal necessidade é o tema central do presente artigo. 


\section{MODELOS DE MATURIDADE}

Para Becker et al. (2009), os modelos de maturidade viabilizam a avaliação do status corrente das organizações e a identificação das possíveis melhorias. Já Almeida Neto et al. (2015), explica que os modelos de maturidade são estruturas conceituais com processos bem definidos para o desenvolvimento sistêmico das organizações visando o alcance de um estado futuro por meio de degraus para um amadurecimento progressivo. Considera-se que o entendimento coletivo do fenômeno de desenvolvimento das organizações é incompleto se não houver uma identificação adequada dos seus estágios de maturidade.

Oliveira (2006) considera que um modelo de maturidade deve possuir: disponibilidade, questionários, avaliações e aderência aos planos estratégicos. Os autores reforçam a importância da aplicabilidade de um modelo. Preza-se pela adaptação dos modelos à cultura organizacional, pela flexibilidade de customização e pelo custo de aplicação.

Durante muito tempo, as pesquisas sobre modelos de maturidade se direcionavam ao desenvolvimento e à engenharia de softwares (WENDLER, 2012). Entretanto, Becker et al. (2009) reforçam a aplicabilidade dos modelos de maturidade em outras áreas do conhecimento. Os autores explicam que os modelos de maturidade podem ser: descritivos com avaliações de capacidades com critérios pré-definidos; prescritivos para direcionar as ações e melhorias práticas; e comparativos para viabilizar benchmarkings internos e externos.

De acordo com Introna et al. (2014), os modelos de maturidade se diferenciam pela estrutura contínua ou por estágios; pelo modo de definir a maturidade; pelas referências aos padrões internacionais, pelos modos de avaliação, pelos resultados e pelas diretrizes para melhorias futuras. Para Demir (2017), os níveis de maturidade organizacional não se restringem à preparação e à execução dos planos estratégicos. É preciso racionalizar os processos de gestão estratégica e alinhar os elementos organizacionais levando em conta as boas práticas de inovação. Costa Filho e Rosa (2017) reforçam que a construção da maturidade requer modelos sistematizados que considerem a avaliação das melhores práticas organizacionais.

Santos e Souza Neto (2013) investigaram a eficácia das avaliações de maturidade da capacidade de governança corporativa de TIC na APF. Cabe destacar que Santos e Souza Neto (2013) também citam a publicação de Xavier (2010) sobre como mensurar a maturidade governança de TIC na Administração Pública Direta Federal. Para avaliar a maturidade da governança de TIC, Santos e Souza Neto (2013) elencaram os aspectos: Confiabilidade, 
Repetitividade, Consistências dos Resultados em Novas Medições, Simplicidade dos Questionários, Autoavaliação e Foco Restrito aos Processos de Governança Corporativa de TIC.

Diante dos modelos citados, o presente trabalho dá continuidade às pesquisas de Xavier (2010) e de Santos e Souza Neto (2013). Essa escolha se justifica pelo fato de o modelo ser direcionado ao SISP e por Xavier (2010) ter elaborado um modelo simplificado de avaliação da maturidade da governança de TIC na Administração Direta Federal, enquanto Santos e Souza Neto (2013) investigaram a eficácia das avaliações de maturidade da capacidade de governança TIC na APF.

\section{GOVERNANÇA DE TIC}

As organizações com maiores níveis de maturidade em governança de TIC possuem desempenhos financeiros superiores (Silva, 2009). Para Weill e Ross (2006) e Baines e Lightfoot (2013), a governança de TIC alinha os objetivos de negócio e tecnológicos com vistas à melhoria do desempenho organizacional. Para tanto, observa-se no médio e longo prazo a redução de custos e o melhor aproveitamento do capital de TIC (WEILL; ROSS, 2006; LUNARDI et al., 2014).

A EGTIC definida pelo SISP no âmbito Federal visa ao aumento da maturidade dos processos de governança de TIC. Nesse contexto, Reis (2016) sugere avaliações de maturidade para governança de TIC. O autor identificou na literatura quais são os Fatores Críticos de Sucesso (FCS) para a implantação de uma governança de TIC, categorizou junto aos especialistas o nível crítico dos FCS levantados, obteve a percepção dos gestores da APF sobre esses FCS e propôs um rol de FCS para se implantar a governança de TIC na APF. Como parte do seu levantamento, sugeriu a avaliação da maturidade dos processos de governança de TIC selecionados e afirmou que os FCS variam de acordo com o grau de maturidade em governança de TIC nas organizações.

\subsection{GOVERNANÇA DE TIC NA APF}

A governança pública organiza a administração do Estado em consonância com os sistemas de normas e leis e com as demandas dos cidadãos. A governança de TIC no setor público enfatiza a transparência e a prestação de contas. Visam-se decisões de TIC perenes e com valor público (LUCIANO; MACADAR, 2016).

De acordo com Santos e Souza Neto (2013), a governança de TIC na APF possui um viés diferenciado visto que os seus investimentos devem agregar valor à sociedade. Os 
processos de governança alinham TIC, negócio e, nesse caso específico, os interesses da população. Trata-se de uma atribuição complexa visto que a governança de TIC no setor governamental deve atender aos preceitos da legalidade sem incorrer custos desnecessários. Na visão de Silva e Souza Neto (2014), a implementação governança de TIC na APF não é trivial, pois envolvem variáveis como satisfação dos usuários dos serviços públicos e qualidade dos produtos entregues aos cidadãos.

O Guia de GovTIC é um referencial de governança de TIC para os integrantes do SISP com práticas para impulsionar a alta administração na otimização dos recursos de TIC. Cabe destacar que a elaboração de um modelo de governança de TIC não se traduz no funcionamento imediato dessa nas organizações. Além disso, processos de governança defasados não geram eficiência (SISP, 2017). Na APF brasileira, a governança de TIC deve assegurar que a utilização da TIC gere valor ao negócio com riscos toleráveis. Trata-se de uma responsabilidade da alta administração das instituições (TCU, 2014).

\section{PROCEDIMENTOS METODOLÓGICOS}

O escopo do modelo proposto neste trabalho abrange os órgãos do Poder Executivo Federal integrantes do SISP. O método empregado foi estruturado em dois momentos. No primeiro momento foi realizada uma análise da literatura sobre o tema, para delineamento dos critérios de maturidade em governança de TIC, seu referencial teórico, e as justificativas de relevância dos mesmos. Num segundo momento, foi realizada uma análise documental no material disponibilizado pelo SISP, para, a partir dos critérios identificados e na relação entre eles, identificar a concepção dos critérios segundo o SISP.

Para a análise qualitativa dos dados desta pesquisa, utilizaram-se as técnicas da análise de conteúdo segundo a perspectiva apresentada por Bardin (1977). Nessa perspectiva, a técnica consiste na exploração dos materiais pesquisados por meio da transformação de recortes de textos em unidades de registros que serão posteriormente agregadas em categorias temáticas. Ao analisar conteúdos, o pesquisador busca compreender os significados de fenômenos específicos (BARDIN, 2011). Para a realização de tal trabalho é imprescindível que fique claro o processo de seleção de artigos, pois a base teórica será dependente desse processo. Nesse sentido foram explorados documentos disponíveis no Portal da Capes, durante o período de março de 2018. 
A existência de uma lacuna de orientações sobre como avaliar a maturidade da governança e gestão de TIC no Governo Federal justifica a relevância dessa pesquisa. Como reforço, Rodrigues (2010) explica que existem poucas referências a respeito da governança de TIC na esfera governamental, fato que sugere estudos aprofundados sobre esse assunto. Convém salientar a constatação do TCU de que a adoção das boas práticas de governança de TIC se encontra distante dos parâmetros considerados ideias para a APF (TCU, 2015).

O protocolo de pesquisa se baseou na metodologia PICO para revisões de literatura. Tal acrônimo se refere aos termos Problema, Intervenção, Comparação e Outcomes. Visualiza-se como problema a baixa maturidade em governança de TIC nos órgãos da Administração Federal Brasileira. Como intervenção, propõe-se avaliar, diagnosticar e aprimorar as ações de governança e gestão de TIC. Com isso, podem-se utilizar as lições aprendidas como benchmarking de comparação para que outros órgãos do SISP aprimorem a governança e a gestão de TIC. O outcome consiste em um processo de diagnóstico e melhoria da governança de TIC no Executivo Federal.

A seleção dos artigos se deu por meio de buscas referentes aos conceitos de modelos de maturidade, avaliação da governança de TIC, maturidade em governança de TIC, modelos de maturidade para governança de TIC, governança de TIC no setor público e governança de TIC na Administração Federal nas bases de dados acadêmicas.

Priorizaram-se os artigos mais recentes, mais citados e que discorreram sobre maturidade em governança de TIC. A leitura preliminar dos resumos, introduções e conclusões das publicações permitiu a definição dos seguintes critérios de descarte: (i) Artigo publicado há mais de 5 anos; (ii) Publicações que discorrem isoladamente sobre governança de TIC; e/ou (ii) Publicações que discorrem isoladamente sobre Administração Federal.

O conteúdo textual de documentos foi recortado em unidades de registro como palavras, frases e parágrafos. Esses fragmentos permitem identificar palavras-chaves categorizáveis. Agrupam-se essas primeiras palavras conforme os assuntos correlacionados e, com isso, surge a macrocategoria. Essa categoria ampla permitirá a elaboração de categorias e subcategorias de palavras (BARDIN, 1977). Bardin (2011) complementa que a categorização é uma forma de classificar elementos. Essas categorias reúnem grupos de elementos que são agrupados pelas suas características comuns. O modelo aberto intuitivo gera categorizações por meio do processo de classificação progressiva dos elementos em que os títulos conceituais 
das categorias são definidos ao finalizar a operação. O detalhamento das etapas de realização dessa técnica está descrito no Quadro 1.

De posse, da estruturação das unidades de registro, categorias e metacategorias, partiuse para o segundo momento, a análise documental do conteúdo disponibilizado pelo SISP, a estruturação da Teoria Fundamentada e do modelo de maturidade de governança e gestão de TIC na APF.

Segundo Fragoso, Recuero e Amaral (2011), a aplicação da Teoria Fundamentada é um processo de coleta e análise de dados que se repete até atingir uma saturação teórica, isto é, não for possível localizar mais dados relevantes. O pesquisador define o propósito da pesquisa, coleta os dados, codifica, categoriza, interpreta e documenta os seus passos. Dentro do escopo deste trabalho, a pergunta pertinente é "o que é maturidade em governança e gestão de TIC para os órgãos vinculados ao SISP?”. O levantamento dos modelos de maturidade em governança de TIC e das publicações de referência do SISP subsidiou a etapa de coleta de dados. O processo é organizado basicamente em três etapas: codificação, categorização e escrita da teoria. Outra nomenclatura para as fases é: codificação aberta, focalizada e seletiva. Segundo Strauss e Corbin (1990) e Fragoso, Recuero e Amaral (2011), na codificação aberta os conceitos são identificados a fim de se desenvolver as suas propriedades e dimensões. Trata-se de um procedimento para ramificar, analisar, comparar e categorizar dados que serão resumidos em linhas, códigos ou categorias. Nessa pesquisa, a codificação aberta foi útil para categorizar o fenômeno da maturidade em governança e gestão de TIC.

De posse das categorias, partiu-se para as respostas às perguntas propostas por Fragoso, Recuero e Amaral (2011): qual fenômeno está ocorrendo? O que os dados expressam? Em quais categorias se classificam os dados?

Conforme Gasque (2007), a codificação axial ou focalizada diferencia e aprimora as categorias resultantes da codificação aberta. As categorias relevantes são escolhidas, definemse as relações de categorias e subcategorias e, por fim, agrupam-se os dados por meio das ligações entre as categorias. O objetivo é interligar e confrontar essas categorias, comparar os conceitos e códigos e, se for o caso, refinar as perguntas da pesquisa. A codificação seletiva é a etapa de elaboração dos conceitos e elaboração da Teoria.

De posse dos conceitos elaborados via Teoria Fundamentada, desenvolveram-se os elementos, estágios evolutivos e domínios de um modelo de maturidade. Na sequência, foram integradas as práticas para se avaliar a maturidade da governança e gestão de TIC nos órgãos 
do SISP. O Quadro 1, explicita o método realizado no desenvolvimento da pesquisa, apresentando o objetivo de cada etapa e as técnicas aplicadas para obtenção dos resultados.

Quadro 1: Método aplicado na pesquisa

\begin{tabular}{|c|c|c|c|}
\hline $\begin{array}{l}\text { Etapa da } \\
\text { pesquisa/Técnica }\end{array}$ & $\begin{array}{l}\text { Etapa do } \\
\text { Método Teórico }\end{array}$ & Objetivo da Etapa & Técnicas aplicadas \\
\hline \multirow{4}{*}{$\begin{array}{l}\text { Primeiro } \\
\text { Momento/ } \\
\text { Análise de } \\
\text { Conteúdo }\end{array}$} & $\begin{array}{l}\text { Seleção dos } \\
\text { Documentos de } \\
\text { análise; Leitura } \\
\text { preliminar; }\end{array}$ & $\begin{array}{lcr}\text { Seleção } & \text { da } & \text { Base } \\
\text { teórica } & \text { que } & \text { será } \\
\text { analisada } & \text { e } & \text { leitura } \\
\text { preliminar } & & \text { dos } \\
\text { artigos. } & & \end{array}$ & $\begin{array}{l}\text { Mineração de artigos utilizando um } \\
\text { protocolo de pesquisa PICO } \\
\text { (problema, } \\
\text { comparação e outcome. }\end{array}$ \\
\hline & $\begin{array}{lr}\text { Recorte } & \text { do } \\
\text { material } & \text { em } \\
\text { unidades } & \text { de } \\
\text { registro } & \\
\text { comparáveis } & \text { e } \\
\text { com conteúdo } \\
\text { semânticos } \\
\text { semelhantes; }\end{array}$ & $\begin{array}{lr}\begin{array}{l}\text { Exploração } \\
\text { selecionados }\end{array} & \text { artigos } \\
\text { transformar } & \text { recortes } \\
\text { de textos em } & \text { unidades } \\
\text { de registros. } & \\
\text { Estruturação } & \text { das } \\
\text { categorias; }\end{array}$ & $\begin{array}{l}\text { - As unidades de registro foram } \\
\text { definidas para representar tópicos } \\
\text { abordados nos modelos de } \\
\text { maturidade de governança de TIC. } \\
\text { - Os tópicos foram identificados } \\
\text { em cada texto, houve um registro } \\
\text { dos questionamentos e discussões } \\
\text { envolvidas e a base teórica } \\
\text { vinculada. A semântica das } \\
\text { diferentes abordagens foi } \\
\text { explorada e registrada. } \\
\text { - A estruturação das categorias } \\
\text { surgiu da dimensão de discussão } \\
\text { apresentada pela literatura, dos } \\
\text { aspectos envolvidos e das possíveis } \\
\text { áreas de evolução da maturidade. }\end{array}$ \\
\hline & $\begin{array}{l}\text { Definição da } \\
\text { macrocategoria de } \\
\text { análise }\end{array}$ & $\begin{array}{ll}\text { Definição } & \text { da } \\
\text { macrocategoria } & \end{array}$ & $\begin{array}{l}\text { - Foi definida de acordo com o } \\
\text { objeto principal da pesquisa. }\end{array}$ \\
\hline & $\begin{array}{lr}\text { Agrupamento } & \text { das } \\
\text { unidades } & \text { de } \\
\text { registro } & \text { em } \\
\text { categorias } & \mathrm{e} \\
\text { subcategorias } & \\
\text { comuns. } & \end{array}$ & $\begin{array}{ll}\text { Criação } & \text { da } \\
\text { Categorização } & \end{array}$ & $\begin{array}{l}\text { - O vínculo entre as unidades de } \\
\text { registro em categorias e } \\
\text { subcategorias comuns se deu pela } \\
\text { análise da base teórica retirada da } \\
\text { literatura. }\end{array}$ \\
\hline \multirow{3}{*}{$\begin{array}{l}\text { Segundo } \\
\text { Momento/ Teoria } \\
\text { Fundamentada e } \\
\text { desenvolvimento } \\
\text { do Modelo de } \\
\text { maturidade de } \\
\text { Governança e } \\
\text { Gestão de TIC } \\
\text { para o SISP. }\end{array}$} & \begin{tabular}{lr}
\multicolumn{2}{l}{ Transformação } \\
das unidades & de \\
registro & em \\
termos & de \\
pesquisa; &
\end{tabular} & $\begin{array}{lr}\text { Redução } & \text { dos } \\
\text { constructos "unidades } \\
\text { de pesquisa" } & \text { para } \\
\text { estruturas } & \text { mais } \\
\text { compactas, } & \\
\text { denominados } & \text { "termos } \\
\text { de pesquisa". } & \end{array}$ & $\begin{array}{l}\text { O processo foi realizado pela } \\
\text { análise sintática da estrutura dos } \\
\text { termos e possíveis reduções. Para } \\
\text { exemplificar o processo, a unidade } \\
\text { de registro "lideranças" no termo } \\
\text { de pesquisa "líder" que pode captar } \\
\text { nos textos do SISP fragmentos } \\
\text { relacionados que utilizam } \\
\text { constructos "liderados", "liderado", } \\
\text { "liderança", "líder", entre outros. }\end{array}$ \\
\hline & $\begin{array}{lr}\text { Levantamento da } \\
\text { documentação do } \\
\text { SISP sobre } \\
\text { governança de } \\
\text { TIC; aplicação } \\
\text { dos termos de } \\
\text { pesquisa; r e } \\
\text { separação dos } \\
\text { fragmentos; }\end{array}$ & $\begin{array}{l}\text { Seleção do material } \\
\text { do SISP. } \\
\text { Extração da maior } \\
\text { quantidade } r \\
\text { fragmentos de textos } \\
\text { do Portal do SISP } \\
\text { aderentes ao tema. }\end{array}$ & $\begin{array}{l}\text { O processo foi feito através da } \\
\text { aplicação dos termos de pesquisa } \\
\text { na documentação. Esses textos } \\
\text { foram armazenados e os } \\
\text { fragmentos relevantes foram } \\
\text { separados. }\end{array}$ \\
\hline & Codificação & objetivo & O processo foi realizado \\
\hline
\end{tabular}




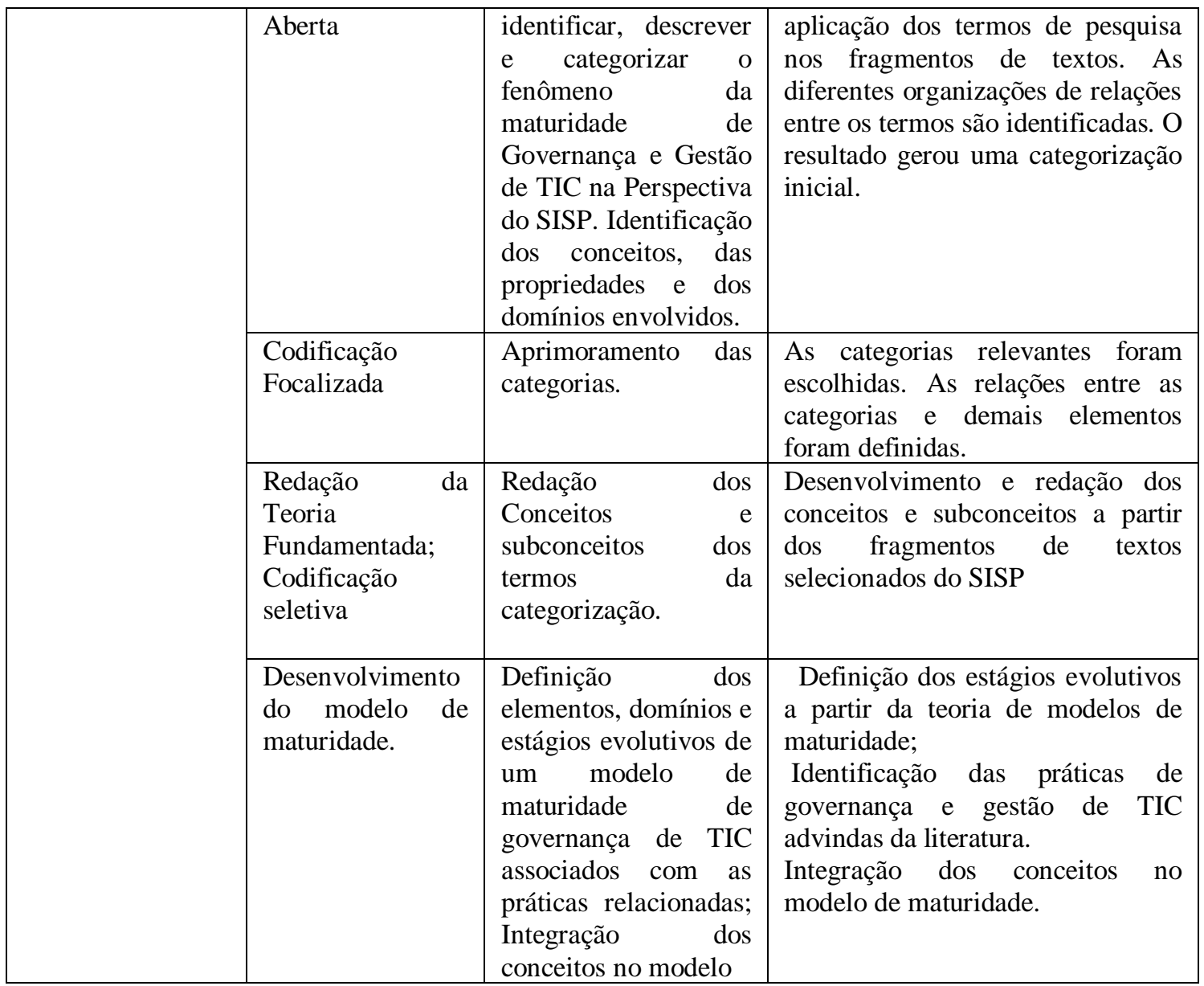

\section{RESULTADOS}

\subsection{CRITÉRIOS DE MATURIDADE EM GOVERNANÇA E GESTÃO DE TI}

O ponto de partida para a análise dos critérios de maturidade, por meio da aplicação da técnica "análise de conteúdo", está intrinsecamente conectado com o conjunto de artigos selecionados para o trabalho. A consulta ocorreu no Portal da CAPES e foram obtidos o conjunto de artigos explícito no Quadro 2.

Quadro 2. Relação dos artigos de referência. 


\begin{tabular}{|c|c|c|c|}
\hline Título do artigo & Autores & Lacunas & Contribuições \\
\hline $\begin{array}{l}\text { An Exploratory Study into } \\
\text { IT Governance } \\
\text { Implementations and its } \\
\text { Impact on Business/IT } \\
\text { Alignment }\end{array}$ & $\begin{array}{l}\text { De Haes e Van } \\
\text { Grembergen (2009) }\end{array}$ & $\begin{array}{l}\text { Impactos da } \\
\text { implementacão da } \\
\text { governança de TI no } \\
\text { alimhamento entre TI e } \\
\text { negócio. }\end{array}$ & $\begin{array}{l}\text { Metodologia para implementacão } \\
\text { prática da govemança de TI. }\end{array}$ \\
\hline $\begin{array}{l}\text { An Empirical Examination } \\
\text { of Maturity Model as } \\
\text { Measurement of Information } \\
\text { Technology Governance } \\
\text { Implementation }\end{array}$ & $\begin{array}{l}\text { A. Abu Khadra, } \\
\text { Zuriekat e Alramhi } \\
(2009)\end{array}$ & $\begin{array}{l}\text { Avaliação da } \\
\text { implementacão da } \\
\text { governança de TI em } \\
\text { organizações não } \\
\text { bancárias. }\end{array}$ & $\begin{array}{l}\text { Implementacão da governança de } \\
\text { TIno setor bancário. }\end{array}$ \\
\hline $\begin{array}{l}\text { Information technology } \\
\text { governance: an evaluation of } \\
\text { the theory-practice gap }\end{array}$ & $\mathrm{K}_{Q}$ e Fink (2010) & $\begin{array}{l}\text { Melhoria do } \\
\text { entendimento sobre } \\
\text { governança de TI pela } \\
\text { alta gestão. }\end{array}$ & $\begin{array}{l}\text { Descrição da implementacão da } \\
\text { governança de TI. }\end{array}$ \\
\hline $\begin{array}{l}\text { Mensuracão da maturidade } \\
\text { da governança de TIC na } \\
\text { administração direta federal } \\
\text { brasileira }\end{array}$ & Xavier (2010) & $\begin{array}{l}\text { Análise da eficácia das } \\
\text { avaliaçóes maturidade } \\
\text { em governança de TI. }\end{array}$ & $\begin{array}{l}\text { Avaliação da govemança de TI } \\
\text { no setor público. }\end{array}$ \\
\hline $\begin{array}{l}\text { A Fuzzy Multicriteria } \\
\text { Approach for IT Govemance } \\
\text { Evaluation }\end{array}$ & $\begin{array}{l}\text { Cobo, Vanti e Rocha } \\
(2014)\end{array}$ & & $\begin{array}{l}\text { Abordagem multicritério para } \\
\text { avaliar a governança de TI } \\
\text { quanto ao alimhamento entre TI e } \\
\text { negócio. }\end{array}$ \\
\hline $\begin{array}{l}\text { Un enfoque de buenas } \\
\text { practicas de gobjerno } \\
\text { corporativo de TI }\end{array}$ & $\begin{array}{l}\text { Yelasquez Perez, } \\
\text { Puentes Yelasquez e } \\
\text { Perez Perez (2015) }\end{array}$ & $\begin{array}{l}\text { Guia de implementacão } \\
\text { da governança de TI. }\end{array}$ & $\begin{array}{l}\text { Modelo para definição de } \\
\text { critérios de governança de TI. }\end{array}$ \\
\hline $\begin{array}{l}\text { IT Governance Evaluation: } \\
\text { Adapting and Adopting the } \\
\text { COBIT Framework for } \\
\text { Public Sector Organisations }\end{array}$ & AlOmari (2016) & $\begin{array}{l}\text { Efetividade da } \\
\text { Governança de TI. }\end{array}$ & $\begin{array}{l}\text { Avaliação da govemança de TI } \\
\text { no setor público. }\end{array}$ \\
\hline $\begin{array}{l}\text { Governança de Tecnologia } \\
\text { da Informação: Uma Análise } \\
\text { do Nivel de Maturidade em } \\
\text { Empresas Atuantes no Brasil }\end{array}$ & $\begin{array}{l}\text { DePaiva Gonçalves, } \\
\text { Antônio Gaspar e } \\
\text { Cardoso (2016) }\end{array}$ & $\begin{array}{l}\text { Como as organizações } \\
\text { sepreparam para } \\
\text { melhorar a maturidade } \\
\text { em governança de TI. }\end{array}$ & $\begin{array}{l}\text { Maturidade em govemança de TI } \\
\text { no contexto brasileiro. }\end{array}$ \\
\hline $\begin{array}{l}\text { IT governance in the public } \\
\text { sector: a conceptual model }\end{array}$ & Tonelli et al. (2017) & \begin{tabular}{|l|} 
Resultados e \\
contribuições da \\
governança de TI.
\end{tabular} & $\begin{array}{l}\text { Demonstração da correlação } \\
\text { positiva entre desempenho da TI } \\
\text { edesempenho organizacional. }\end{array}$ \\
\hline
\end{tabular}

Para o levantamento dos critérios da maturidade em governança e gestão de TIC, analisaram-se os artigos supracitados para identificar os tópicos abordados, questionamentos relevantes, a base teórica vinculada e as justificativas das mesmas. Os Quadros 3 e 4 apresentam uma amostra desse levantamento realizado nas publicações de De Paiva Gonçalves, Antônio Gaspar e Cardoso (2016) e Tonelli et al. (2017). Aplicou-se esse mesmo raciocínio em todos os artigos acima apresentados.

Quadro 3. Bases teóricas - De Paiva Gonçalves, Antônio Gaspar e Cardoso (2016)

\begin{tabular}{|c|c|c|c|}
\hline \multicolumn{4}{|c|}{ De Paiva Gonçalves, Antônio Gaspar e Cardoso (2016) } \\
\hline Tópicos principais & Questionamentos & Base teórica & Justificativa \\
\hline $\begin{array}{l}\text { Recursos de TIC e } \\
\text { valor agregado. }\end{array}$ & $\begin{array}{l}\text { Os recursos de TIC } \\
\text { entregam valor efetivo } \\
\text { para a organização? }\end{array}$ & $\begin{array}{l}\text { A governança de TIC direciona os } \\
\text { relacionamentos e os processos } \\
\text { para o alcance dos objetivos } \\
\text { institucionais e agregação de valor } \\
\text { (VANNI; 2005). }\end{array}$ & $\begin{array}{ll}\text { Avaliar } & \text { os } \\
\text { resultados } & \text { da } \\
\text { TIC. } & \end{array}$ \\
\hline Estratégias de TIC. & $\begin{array}{l}\text { A atuação da TIC é } \\
\text { tida como estratégica? }\end{array}$ & $\begin{array}{l}\text { A governança de TIC direciona as } \\
\text { práticas de gestão de TIC e as }\end{array}$ & $\begin{array}{l}\text { Reforçar } \\
\text { papel }\end{array}$ \\
\hline
\end{tabular}




\begin{tabular}{|l|l|l|lr|}
\hline & & $\begin{array}{l}\text { estratégias organizacionais (ITGI, } \\
2011) .\end{array}$ & $\begin{array}{l}\text { estratégico da } \\
\text { TIC. }\end{array}$ \\
\hline $\begin{array}{l}\text { Mensuração do do } \\
\text { desempenho da TIC e } \\
\text { desempenho da TIC. }\end{array}$ & $\begin{array}{l}\text { Quais são os processos } \\
\text { para a mensuração do } \\
\text { desempenho da TIC? }\end{array}$ & $\begin{array}{l}\text { A mensuração de desempenho } \\
\text { demonstra o valor da TIC na } \\
\text { organização (ITGI, 2007). }\end{array}$ & $\begin{array}{l}\text { Avaliar os } \\
\text { resultados da } \\
\text { TIC. }\end{array}$ \\
\hline
\end{tabular}

Quadro 4. Bases teóricas - Tonelli et al. (2017)

\begin{tabular}{|c|c|c|c|}
\hline \multicolumn{4}{|l|}{ Tonelli et al. (2017) } \\
\hline Tópicos principais & Questionamentos & Base teórica & Justificativa \\
\hline $\begin{array}{l}\text { Planos e políticas de } \\
\text { TIC. }\end{array}$ & $\begin{array}{l}\text { Quais são as políticas, } \\
\text { planos e procedimentos } \\
\text { mais relevantes das } \\
\text { áreas de TIC? }\end{array}$ & $\begin{array}{l}\text { O alinhamento entre TIC e metas } \\
\text { de negócio é maior quando as } \\
\text { organizações executam práticas de } \\
\text { governança de TIC maduras como } \\
\text { processos, políticas e } \\
\text { planejamentos de TIC (DE HAES, } \\
\text { VAN GREMBERGEN; 2009). }\end{array}$ & $\begin{array}{l}\text { Alinhar as ações } \\
\text { de TIC às metas } \\
\text { de negócio. }\end{array}$ \\
\hline $\begin{array}{l}\text { Desempenho da TIC e } \\
\text { desempenho } \\
\text { organizacional. }\end{array}$ & $\begin{array}{l}\text { Quais são os processos } \\
\text { para a mensuração do } \\
\text { desempenho da TIC e } \\
\text { da organização? }\end{array}$ & $\begin{array}{l}\text { A governança de TIC pode } \\
\text { melhorar o desempenho da } \\
\text { organização (DE HAES, VAN } \\
\text { GREMBERGEN, 2009; LUNARDI } \\
\text { et al. 2014; WEILL, ROSS 2004). }\end{array}$ & $\begin{array}{l}\text { Explicitar as } \\
\text { contribuições } \\
\text { do desempenho } \\
\text { da TIC para o } \\
\text { desempenho } \\
\text { organizacional. }\end{array}$ \\
\hline $\begin{array}{l}\text { Aparato de TIC } \\
\text { tomadas de decisão. }\end{array}$ & $\begin{array}{lr}\text { O aparato de } & \text { TIC } \\
\text { consegue } & \text { apoiar } \\
\text { efetivamente } & \text { os } \\
\text { tomadores de decisão? }\end{array}$ & $\begin{array}{l}\text { Os processos da gestão de TIC } \\
\text { devem operacionalizar e apoiar as } \\
\text { decisões, as regras e as políticas } \\
\text { organizacionais } \\
\text { 2004). }\end{array}$ & $\begin{array}{ll}\text { Apoiar } & \text { os } \\
\text { processos } & \\
\text { decisórios. } & \end{array}$ \\
\hline
\end{tabular}

O Quadro 5 apresenta uma síntese com a relação dos critérios de maturidade em governança e gestão de TIC levantados por meio da análise de conteúdo separados por autor. A partir desses critérios, foi possível extrair unidades de registro para aplicação posterior nas pesquisas na documentação do SISP.

Quadro 5: Critérios de Maturidade e Unidades de Registro vinculadas e identificadas

\begin{tabular}{|c|c|c|}
\hline os & ritérios de maturidade citados & Unidades de Registro \\
\hline $\begin{array}{l}\text { De Haes e Van } \\
\text { Grembergen } \\
(2009)\end{array}$ & $\begin{array}{l}\text { - Os comitês de TIC são atuantes? } \\
\text { - Existe uma estrutura formalizada para o } \\
\text { gerenciamento dos portfólios de TIC? } \\
\text { - Os controles do orçamento de TIC são eficazes? } \\
\text { - Há apoio institucional para as lideranças de TIC? } \\
\text { - Os comitês de TIC direcionam efetivamente os } \\
\text { projetos de TIC? } \\
\text { - Os diretores de TIC possuem apoio da alta } \\
\text { administração? } \\
\text { - Existem metodologias formalizadas para a } \\
\text { governança e gestão de projetos? }\end{array}$ & $\begin{array}{l}\text { - Comitês de TI; } \\
\text { - Gerenciamento } \\
\text { portfólios; } \\
\text { - Controles do orçamento } \\
\text { de TI; } \\
\text { - Lideranças de TI; } \\
\text { - Comitês de direção dos } \\
\text { projetos de TI; } \\
\text { - Diretores de TI; e } \\
\text { - Metodologias de gestão e } \\
\text { governança de projetoes. }\end{array}$ \\
\hline $\begin{array}{l}\text { Abu Khadra, } \\
\text { Zuriekat } \\
\text { Alramhi (2009) }\end{array}$ & $\begin{array}{l}\text { Existem políticas para comunicar e sensibilizar os } \\
\text { funcionários sobre a relevância da TIC? } \\
\text { - Quais são ferramentas tecnológicas para a } \\
\text { automação dos processos de negócio? } \\
\text { - Quais são os responsáveis e prestadores de contas }\end{array}$ & $\begin{array}{l}\text { - Comunicações } \\
\text { sensibilização; } \\
\text { - Ferramentas } \\
\text { automação; } \\
\text { - Responsabilidade }\end{array}$ \\
\hline
\end{tabular}




\begin{tabular}{|c|c|c|}
\hline & $\begin{array}{l}\text { quanto aos recursos e projetos de TIC? } \\
\text { - Quais são as competências e expertises da } \\
\text { organização em tecnologia? } \\
\text { • A área de tecnologia possui ferramentas para } \\
\text { definir e mensurar o alcance das suas metas? } \\
\bullet \quad \text { Quais são os planos, políticas e procedimentos } \\
\text { que direcionam a atuação da área de TIC? }\end{array}$ & $\begin{array}{l}\text { Prestação de contas; } \\
\text { - Competências } \\
\text { Expertise; } \\
\text { - Definiçào e medição de } \\
\text { metas; e } \\
\text { - Políticas, planos e } \\
\text { procedimentos. }\end{array}$ \\
\hline Ko e Fink (2010) & $\begin{array}{l}\text { - Os comitês de TIC viabilizam uma organização } \\
\text { efetiva das áreas e recursos tecnológicos? } \\
\text { - Existem boas práticas de TIC já formalizadas na } \\
\text { instituição? } \\
\text { • A atuação da TIC está alinhada aos objetivos de } \\
\text { negócio? } \\
\text { • Existem mecanismos para a medição do } \\
\text { desempenho da TIC? } \\
\text { - Quais são as áreas e pessoas com capacidades e } \\
\text { papéis de liderança em TIC? } \\
\text { • Quais são as regras e responsabilidades que } \\
\text { norteiam os projetos e áreas de TIC? } \\
\text { • As áreas de TIC possuem uma participação e } \\
\text { compromisso efetivos no alcance dos objetivos } \\
\text { organizacionais? } \\
\text { • Existem políticas para comunicar e sensibilizar os } \\
\text { funcionários sobre a relevância da TIC? }\end{array}$ & $\begin{array}{l}\text { - Organização da TIC; } \\
\text { - Comitês de TIC; } \\
\text { - Boas práticas de TIC; } \\
\text { - Alinhamento da TIC com } \\
\text { negócio; } \\
\text { - Medição do desempenho } \\
\text { da TIC; } \\
\text { - Capacidades e lideranças } \\
\text { de TIC; } \\
\text { - Regras } \\
\text { responsabilidades; } \\
\text { - Compromisso } \\
\text { participação; e } \\
\text { - Sensibilização } \\
\text { compreensão. }\end{array}$ \\
\hline Xavier (2010) & $\begin{array}{l}\text { - Quais são as principais estratégias para se } \\
\text { promover uma sensibilização quanto à importância dos } \\
\text { recursos tecnológicos? } \\
\text { - Quais são as políticas, planos e procedimentos } \\
\text { mais relevantes das áreas de TIC? } \\
\text { - Como a TIC pode apoiar as áreas de negócio com } \\
\text { ferramentas e soluções para automação dos processos } \\
\text { de negócios? } \\
\text { - Quais são as principais habilidades e } \\
\text { conhecimentos dos recursos humanos de TIC? } \\
\text { - Quais áreas de negócio efetivamente se } \\
\text { responsabilizam pelos recursos e projetos de TIC? } \\
\text { - Existem mecanismos formais para mensuração } \\
\text { do alcance das metas? }\end{array}$ & $\begin{array}{l}\text { - Sensibilização } \\
\text { comunicação; } \\
\text { - Políticas, planos } \\
\text { procedimentos; } \\
\text { - Ferramentas } \\
\text { automação; } \\
\text { - Habilidades } \\
\text { conhecimentos; } \\
\text { - Responsabilidade } \\
\text { responsabilização; e } \\
\text { - Metas e mensuração. }\end{array}$ \\
\hline $\begin{array}{l}\text { Cobo, Vanti } \\
\text { Rocha }(2014)\end{array}$ & $\begin{array}{l}\text { - A atuação da TIC está alinhada aos objetivos } \\
\text { estratégicos? } \\
\text { - Os projetos de TIC entregam valor para a } \\
\text { organização? } \\
\text { • Existe uma política efetiva para gerenciamento de } \\
\text { riscos? } \\
\text { • Quais são as ferramentas para se medir o } \\
\text { desempenho da TIC? } \\
\text { - Quais são os processos pertinentes para o } \\
\text { gerenciamento dos recursos de TIC? }\end{array}$ & $\begin{array}{l}\text { - Alinhamento estratégico; } \\
\text { Entrega de valor; } \\
\text { - Gerenciamento de riscos; } \\
\text { - Medição do desempenho } \\
\text { da TIC; e } \\
\text { - Gerenciamento dos } \\
\text { recursos de TIC. }\end{array}$ \\
\hline $\begin{array}{l}\text { Velasquez Perez, } \\
\text { Puentes Velasquez } \\
\text { e Perez Perez } \\
(\mathbf{2 0 1 5 )}\end{array}$ & $\begin{array}{l}\text { - A atuação da TIC é tida como estratégica? } \\
\text { - Quais são os mecanismos e comportamentos para } \\
\text { garantir a conformidade e a responsabilização pelas } \\
\text { aquisições de TIC? }\end{array}$ & $\begin{array}{l}\text { - Estratégia; } \\
\text { - Desempenho; } \\
\text { - Aquisições; } \\
\text { - Responsabilização; } \\
\text { e } \text { Comportamento humano; } \\
\text { - Conformidade. }\end{array}$ \\
\hline Al Omari (2016) & $\begin{array}{l}\text { - A atuação da TIC é tida como estratégica? } \\
\text { - Quais são os mecanismos e comportamentos para } \\
\text { garantir a conformidade e a responsabilização pelas } \\
\text { aquisições de TIC? }\end{array}$ & $\begin{array}{l}\text { - } \quad \text { Políticas; } \\
\text { - } \quad \text { Procedimentos; } \\
\text { - } \quad \text { Comptruturas de TIC; } \\
\text { organizacional; }\end{array}$ \\
\hline
\end{tabular}




\begin{tabular}{|c|c|c|}
\hline & & $\begin{array}{ll}- & \text { Orçamento; } \\
\text { - } & \text { Lideranças; e } \\
\text { - } & \text { Conformidade. }\end{array}$ \\
\hline $\begin{array}{l}\text { De Paiva } \\
\text { Gonçalves, } \\
\text { Antônio Gaspar e } \\
\text { Cardoso (2016) }\end{array}$ & $\begin{array}{l}\text { - A atuação da TIC é tida como estratégica? } \\
\text { - Os recursos de TIC entregam valor efetivo para a } \\
\text { organização? } \\
\text { - Existem políticas formais para a gestão de riscos? } \\
\text { - Quais são os processos para a mensuração do } \\
\text { desempenho da TIC? }\end{array}$ & $\begin{array}{l}\text { - Alinhamento estratégico; } \\
\text { - Entrega de valor; } \\
\text { - Gestão de recursos; } \\
\text { - Gestão de riscos; e } \\
\text { - Mensuração de } \\
\text { desempenho. }\end{array}$ \\
\hline $\begin{array}{l}\text { Tonelli et al. } \\
\text { (2017) }\end{array}$ & $\begin{array}{l}\text { - Quais são as políticas, planos e procedimentos } \\
\text { mais relevantes das áreas de TI? } \\
\text { • Quais são os processos para a mensuração do } \\
\text { desempenho da TIC e da organização? } \\
\text { • O aparato de TIC consegue apoiar efetivamente } \\
\text { os tomadores de decisão? } \\
\text { • A atuação da governança de TIC é vista como } \\
\text { estratégica para a organização? }\end{array}$ & $\begin{array}{l}\text { - Processos de governança } \\
\text { de TIC; } \\
\text { - Processos de gestão de } \\
\text { TIC; Estruturas de tomada de } \\
\text { decisão; } \\
\text { - Desempenho da TIC; e } \\
\text { - Desempenho } \\
\text { organizacional. }\end{array}$ \\
\hline
\end{tabular}

A consolidação das unidades de registros foi obtida por meio dos critérios de maturidade já apresentados. O Quadro 6 apresenta a relação de trabalhos que discorrem sobre cada uma delas.

Quadro 6- Consolidação das unidades de registro

\begin{tabular}{|l|l|}
\hline Autores & Unidades de Registro \\
\hline Ko e Fink (2010) & $\begin{array}{l}\text { Compromisso e Participação } \\
\text { Boas Práticas de TI }\end{array}$ \\
\hline Ko e Fink (2010) e Xavier (2010) & Sensibilização e Compreensão \\
\hline Xavier (2010) & Habilidades e Conhecimento \\
\hline $\begin{array}{l}\text { Abur Khadra, Zuriekat e Alramht (2009), Ko e Fink (2010), Xavier (2010), } \\
\text { Velaskes Peres, Puentes Velaskez e Perez Perez (2015) }\end{array}$ & Responsabilização \\
\hline Tonelli et. al. (2017) & $\begin{array}{l}\text { Estruturas de Tomada de } \\
\text { Decisão }\end{array}$ \\
\hline De Haes e Van Grembergen (2009), Ko e Fink (2010) & Comitês de TI \\
\hline De Haes e Van Grembergen (2009), Ko e Fink (2010) e Al Omari (2016) & Lideranças \\
\hline $\begin{array}{l}\text { A. Abur Khadra, Zuriekat e Alramht (2009), Xavier (2010) e Al Omari } \\
\text { (2016) }\end{array}$ & Políticas \\
\hline A. Abur Khadra, Zuriekat e Alramht (2009), Xavier (2010) & $\begin{array}{l}\text { Planos } \\
\text { Ferramentas e Automação }\end{array}$ \\
\hline Al Omari (2016) & Orçamento \\
\hline Velaskes Peres, Puentes Velaskez e Perez Perez (2015) & Aquisições \\
\hline Velaskes Peres, Puentes Velaskez e Perez Perez (2015) e Al Omari (2016) & Conformidade \\
\hline A. Abur Khadra, Zuriekat e Alramht (2009) e Xavier (2010), & Definição de Metas \\
\hline $\begin{array}{l}\text { Ko e Fink (2010), Cobo, Vanti e Rocha (2014) e De Paiva Gonçalvez, } \\
\text { Gaspar e Cardoso (2016) }\end{array}$ & Alinhamento Estratégico \\
\hline Cobo, Vanti e Rocha (2014), De Paiva Gonçalvez, Gaspar e Cardoso (2016) & $\begin{array}{l}\text { Entrega de Valor } \\
\text { Gestão de Riscos }\end{array}$ \\
\hline Tonelli et. al. (2017) & $\begin{array}{l}\text { Processos de Governança de } \\
\text { TI }\end{array}$ \\
\hline
\end{tabular}

Para esta pesquisa, a macrocategoria foi definida pelo próprio objeto da pesquisa “critérios de maturidade em governança de TI". As categorias foram definidas a partir dos critérios de maturidade em governança de TIC extraídos da literatura pela interpretação da dimensão de perspectiva dos autores. A afinidade de conteúdos abordados foi o critério final 
para validação do acoplamento realizado. O Quadro 7 apresenta a consolidação da Metacategoria, Categorias e Unidades de Registros obtidas.

Quadro 7. Metacategoria, categorias e unidades de registro.

\begin{tabular}{|c|c|c|}
\hline Metacategoria & Categorias & Unidades de registro \\
\hline \multirow{20}{*}{$\begin{array}{l}\text { Critérios de maturidade em } \\
\text { govemança e gestão de TI }\end{array}$} & \multirow{4}{*}{$\begin{array}{l}\text { Cultura } \\
\text { organizacional }\end{array}$} & Compromisso e participação \\
\hline & & Sensibilização e compreensão \\
\hline & & Habilidades e conhecimentos \\
\hline & & Responsabilização \\
\hline & \multirow{8}{*}{$\begin{array}{l}\text { Controles } \\
\text { intemos }\end{array}$} & Estruturas de tomada de decisão \\
\hline & & Comitês de TI \\
\hline & & Lideranças \\
\hline & & Políticas \\
\hline & & Planos \\
\hline & & Orçamento \\
\hline & & Aquisições \\
\hline & & Conformidade \\
\hline & \multirow{8}{*}{$\begin{array}{l}\text { Desempenho } \\
\text { organizacional }\end{array}$} & Definição de metas \\
\hline & & Boas práticas de TI \\
\hline & & Medição do desempenho da TI \\
\hline & & Alinhamento estratégico \\
\hline & & Entrega de valor \\
\hline & & Processos de govemança de TI \\
\hline & & Ferramentas e automação \\
\hline & & Gestão de riscos \\
\hline
\end{tabular}

A categoria 'Cultura organizacional' englobou as unidades de registro 'Compromisso e participação', 'Sensibilização e compreensão', 'Habilidades e conhecimentos' e 'Responsabilização' porque, conforme Mintzberg et al. (2000), cultura organizacional é um sistema de crenças, tradições, hábitos e conhecimentos que diferenciam as instituições umas das outras. Trata-se de uma legitimadora dos conjuntos de valores e de rituais que geram padrões de comportamento aceitos por todos.

Selecionou-se o termo 'Controles internos' para categorizar as unidades de registro 'Comitês de TIC', 'Lideranças', 'Políticas', 'Planos', 'Orçamento', 'Aquisições' e 'Conformidade' pois na visão de Oliveira e Perez Junior (2009), os controles internos são procedimentos conduzidos por comitês decisórios e por lideranças com vistas à conformidade com as legislações aplicáveis, eficiência operacional, tempestividade das medidas corretivas, confiabilidade nas aquisições e gestão orçamentária e eficácia dos planos e políticas organizacionais.

Considerou-se que 'Desempenho organizacional' pode englobar as unidades de registro 'Definição de metas', 'Boas práticas de TIC', 'Medição do desempenho da TIC', 'Alinhamento estratégico', 'Entrega de valor', 'Processos de governança de TIC', 'Ferramentas e automação' e 
'Gestão de riscos' visto que conforme Neely et al. (2000), Teló (2001) e Machado Padilha et al. (2010), o desempenho organizacional envolve considerações quanto à geração de valor agregado, inovações tecnológicas, eficiência, riscos, alinhamento de objetivos e metas, integrações entre departamentos e sistemas de medição e ferramentas de gestão.

\subsection{CONCEITOS OBTIDOS PELA TEORIA FUNDAMENTADA}

A partir das categorizações obtidas com a Análise de Conteúdo, desenvolveu-se termos de pesquisa. O Quadro 8 apresenta as unidades de registro e seus respectivos termos de pesquisas.

Quadro 8. Termos de pesquisa.

\begin{tabular}{|c|c|}
\hline Unidades de registro & Termos de pesquisa \\
\hline Compromisso e participação & "comprom' e 'particip" \\
\hline Sensibilização e compreensão & 'sensi e 'compreen' \\
\hline Habilidades e conhecimentos & 'habili' e 'conhec' \\
\hline Responsabilização & "respons' \\
\hline Estruturas de tomada de decisão & 'estrut', 'toma'e 'deci' \\
\hline Comitês de TI & 'comi' \\
\hline Lideranças & 'Lider' \\
\hline Políticas & "polit' \\
\hline Planos & "plan' \\
\hline Orçamento & "orça" \\
\hline Aquisições & 'aguisic' \\
\hline Conformidade & 'sonformidad' \\
\hline Definição de metas & 'meta' \\
\hline Boas práticas de TI & 'pratic' \\
\hline Medição do desempenho da TI & 'medi' e 'desemp' \\
\hline Alinhamento estratégico & 'alinh' e 'estrateg' \\
\hline Entrega de valor & 'entreg' e 'valor' \\
\hline Processos de govemança de TI & 'process' e 'goxem' \\
\hline Ferramentas e automação & 'ferramenta' e 'automa' \\
\hline Gestão de riscos & 'gest' e 'nisc' \\
\hline
\end{tabular}

A aplicação dos termos de pesquisa nos textos do SISP gerou dois grupos de resultados. Um grupo de termos não retornaram fragmentos de textos envolvendo governança e gestão de TI na APF. Esse foi o caso dos seguintes termos: 'sensi', 'compreens', 'habili', 'automa', 'gest', 'estrut', 'toma', 'deci', 'pratic', 'comi', 'process', 'govern', 'lider', 'polit', 'orça', 'aquisiç', 'medi', 'desemp', 'estra' e 'entreg'. A partir da aplicação dos demais termos foram selecionados os trechos para a aplicação da Teoria Fundamentada. 
Na etapa "codificação aberta" foram identificados conceitos em conjunto com suas propriedades e dimensões. Por meio das categorias Comportamento, Comprometimento, Alinhamento, Indicadores, Alta administração e Planos de TIC, percebeu-se que o fenômeno da maturidade em governança e gestão de TIC pode envolver comportamentos e indicadores para o alinhamento dos planos de TIC com as diretrizes da alta administração. Através das categorias Comitês, Processos, Projetos, Responsabilidades, Áreas de negócio, Entrega de valor, Governança de TIC e SISP, observou-se que a maturidade em governança e gestão de TIC no SISP pode expressar considerações sobre processos, projetos, comitês e responsabilidades para entrega de valor às áreas de negócio. As categorias PDTIC, Partes interessadas, Objetivos corporativos, Tomada de decisão, Priorização, Desempenho, Conformidade, Segurança da informação, Auditoria, Objetivos estratégicos de TIC, Planos de investimentos, Capacitação, Riscos de TIC, Soluções de TIC, Aquisições de TIC, Planejamento estratégico, Contratos de TIC, Riscos contratuais e Incidentes mostraram que os planejamentos estratégicos, PDTIC e planos de investimentos podem considerar: objetivos corporativos, interesses das partes interessadas, auditorias, desempenho, conformidades, segurança da informação e objetivos estratégicos de TIC para evitar riscos de TIC, incidentes e riscos contratuais nos contratos e aquisições de TIC.

Segundo as categorias Metas, Gestão de TIC, Avaliação de resultados, Estratégia, Planejamento de TIC, EGTIC, Direcionamento, Prestação de contas, Serviços de TIC, Projetos de TIC, Efetividade, Portfólio de TIC, PETIC e PEI, os documentos EGTIC, PETIC, PEI podem direcionar as estratégias, portfólios, planejamentos, gestões, projetos e serviços de TIC com vistas à efetividade por meio das prestações e contas e avaliações de resultados. Já as categorias Metas do negócio, Plano de metas e ações, Prazos, Recursos humanos, Orçamento, Eficácia, Qualidade, Custos e Iniciativas expressaram que os planos de metas, ações e iniciativas podem gerar eficácia e qualidade na gestão de prazos, orçamentos e recursos humanos. As categorizações Estratégia de TIC, Integração, Diretrizes estratégicas, Ações de TIC, Recursos de TIC, Governança corporativa e Cultura organizacional expressam que a governança corporativa e a cultura organizacional podem viabilizar as diretrizes estratégicas na integração de ações e recursos de TIC.

As categorias Ameaças, Oportunidades, Conhecimentos, Práticas, Habilidades e Gerenciamento de projetos mostraram que a maturidade em governança de TIC pode levar em conta as ameaças, oportunidades, conhecimentos, práticas e habilidades no gerenciamento dos 
projetos de TIC. Por fim as categorias Eventos, Riscos de projetos, Gestão de riscos, Ameaças, Processos finalísticos, Processos de apoio, Processos gerenciais, Competências e Continuidade expressaram que a maturidade na governança de TIC pode exigir competências em gestão de riscos para que os eventos e ameaças nos projetos de TIC e nos processos finalísticos, de apoio e gerenciais não prejudiquem a continuidade dos serviços de TIC.

Realizada a codificação aberta, partiu-se para a codificação focalizada das categorias. Conforme Gasque (2007), a codificação axial ou focalizada diferencia e aprimora as categorias resultantes da codificação aberta. Além disso, o objetivo é interligar e confrontar as categorias, comparar os conceitos e códigos e, se for o caso, refinar as perguntas da pesquisa. Esse processo gerou as seguintes inferências:

1. O fenômeno da maturidade em governança e gestão de TIC pode envolver comportamentos e indicadores para o alinhamento dos planos de TIC com as diretrizes da alta administração;

2. A maturidade em governança e gestão de TIC no SISP pode expressar considerações sobre processos, projetos, comitês e responsabilidades para entrega de valor às áreas de negócio;

3. Os planejamentos estratégicos, PDTIC e planos de investimentos podem considerar: objetivos corporativos, interesses das partes interessadas, auditorias, desempenho, conformidades, segurança da informação e objetivos estratégicos de TIC para evitar riscos de TIC, incidentes e riscos contratuais nos contratos e aquisições de TI;

4. Os documentos EGTIC, PETIC, PEI podem direcionar as estratégias, portfólios, planejamentos, gestões, projetos e serviços de TIC com vistas à efetividade por meio das prestações de contas e avaliações de resultados;

5. Os planos de metas, ações e iniciativas podem gerar eficácia e qualidade na gestão de prazos, orçamentos e recursos humanos;

6. A governança corporativa e a cultura organizacional podem viabilizar as diretrizes estratégicas na integração de ações e recursos de TIC;

7. A maturidade em governança e gestão de TIC pode considerar as ameaças, oportunidades, conhecimentos, práticas e habilidades na gestão dos projetos de TIC; e

8. A maturidade na governança de e gestão TIC pode exigir competências em gestão de riscos para que os eventos e ameaças nos projetos de TIC e nos processos finalísticos, de apoio e gerenciais não prejudiquem a continuidade dos serviços de TIC. 
Com base nessas inferências, realizou-se o aprimoramento das categorias. De posse da macrocategoria e das categorias (Quadro 7), percebeu-se a necessidade de gerar subcategorias para obter uma estrutura mais refinada, considerando as unidades de registro extraídas da análise de conteúdo aplicada à literatura.

A primeira inferência permitiu a visualização da macrocategoria e das categorias Comportamentos, Indicadores, Objetivos da alta administração, Objetivos da TIC, Planos de TIC e Diretrizes da alta administração e Diretrizes da TIC. A segunda inferência gerou as categorias Processos de negócio, Processos de TIC, Projetos de TIC, Entrega de valor, Comitês estratégicos, Comitês de TIC, Responsabilidades e Unidades de negócio.

A terceira inferência originou as categorias Planejamentos estratégicos, Planejamentos de TIC, Planos de investimentos em TIC, PDTIC, Interesses das partes interessadas, Auditorias, Desempenho, Conformidades, Segurança da Informação, Riscos de TIC, Riscos contratuais, Contratos de TIC e Aquisições de TIC. Já a quarta inferência permitiu a visualização das categorias EGTIC, PETIC, PEI, Estratégias de TIC, Portfólios de TIC, Gestão de TIC, Serviços de TIC, Efetividade, Prestações de contas e Avaliações de resultados. A quinta inferência refinou as categorias: Planos de metas, Iniciativas de TIC, Eficácia, Qualidade, Prazos, Orçamentos de TIC, Recursos humanos e Recursos de TIC.

A sexta inferência deu origem às categorias Governança corporativa e Cultura organizacional. Já a sétima inferência gerou as categorias Ameaças, Oportunidades, Conhecimentos, Práticas, Habilidades e Gerenciamento de projetos de TIC. Por fim, a oitava inferência originou as categorias Gestão de riscos, Eventos, Processos finalísticos, Processos de apoio, Processos gerenciais e Continuidade.

A partir da definição da macrocategoria e do desenvolvimento de conceitos, refinamento e consolidação das unidades de registro e das categorias obtidas tanto da literatura quanto pela aplicação da Teoria Fundamentada, chega-se num processo refinado de categorização que contém subcategorias. A macrocategoria "Maturidade em Governança e Gestão de TIC" possui três categorias "Cultura Organizacional”, “Controles Internos" e "Desempenho Organizacional”. A “Cultura Organizacional” apresenta três elementos: sensibilização, treinamentos e prestações de contas. Os "Controles Internos" apresentam os seguintes elementos: conformidade, gestão de riscos, riscos de TIC, Gestão de TIC, Serviços de TIC, Iniciativas de TIC e Planos de TIC. O "Desempenho Organizacional" apresenta quatro elementos: entrega de valor, continuidade, efetividade, e definição de 
responsabilidades. É importante ressaltar que para algumas categorias geradas não foi possível desenvolver os conceitos, como por exemplo, Eventos, processos de apoio e prazos.

A redação da teoria baseada nas documentações do SISP, fase de codificação seletiva, foi iniciada com o desenvolvimento dos conceitos e subconceitos tomaram por base fragmentos de textos da documentação do SISP. Extraíram-se os trechos pertinentes e, por meio da análise desses, elaboraram-se as conceituações dos termos já categorizados.

O Quadro 9 apresenta os conceitos originados a partir da aplicação das fases da Teoria Fundamentada, isto é, os entendimentos sobre maturidade em governança e gestão de TIC com base nas documentações do SISP.

Cabe aqui destacar as diferenças e similaridades entre os conceitos obtidos pela Teoria Fundamentada nas documentações do SISP e os entendimentos advindos da literatura científica. A seguir são apresentadas algumas análises dos conceitos formulados frente aos descritos na literatura.

Para Mintzberg et al. (2000), cultura organizacional é um sistema de crenças, tradições, hábitos e conhecimentos para diferenciar as instituições. Para o SISP, a cultura organizacional é considerada no âmbito da gestão de riscos e tomadas de decisões pela alta administração. Trata-se de um conceito restrito devido à abrangência conceitual que a cultura atua.

Butzke, Pereira e Noebauer (2007) entendem sensibilização como a transmissão de conhecimentos genéricos às partes interessadas por meio da divulgação de programas, projetos e atividades. O SISP vê na sensibilização uma forma de engajar a cultura organizacional e alta administração na gestão dos riscos de TIC. 
Quadro 9. Conceitos obtidos via Teoria Fundamentada.

\begin{tabular}{|c|c|}
\hline Termo & Conceito \\
\hline $\begin{array}{l}\text { Cultura } \\
\text { organizacional }\end{array}$ & $\begin{array}{l}\text { A cultura organizacional deve considerar a atuaçåo da alta } \\
\text { administração na gestão dos riscos de TI e nas tomadas de } \\
\text { decisões colegiadas. }\end{array}$ \\
\hline Sensibilização & $\begin{array}{l}\text { Uma maneira de engajar a cultura organizacional e alta } \\
\text { administração na gestăo dos riscos de TI. }\end{array}$ \\
\hline Treinamento & Capacitação do pessoal de TI respaldado pelo PDTI. \\
\hline Prestação de contas & $\begin{array}{l}\text { Avaliaçáo dos planos, projetos e serviços de TI considerando } \\
\text { as metas e decisões organizacionais. }\end{array}$ \\
\hline Conformidade & $\begin{array}{l}\text { Objetivo conjunto dagovemançade TI e da alta administraçăo } \\
\text { traduzido pela aderência às disposições regulamentares, } \\
\text { legislativas e contratuais. }\end{array}$ \\
\hline Gestão de riscos & $\begin{array}{l}\text { A gestão de riscos deve pos suir umplanejamento e pas sar pela } \\
\text { aprovação do Comitê de TI e da alta administração. }\end{array}$ \\
\hline Riscos de TI & $\begin{array}{l}\text { Os riscos de TI exigemo engajamento da alta administraçá, } \\
\text { pois possuem efeitos nos processos finalisticos, de apoio e } \\
\text { gerenciais. }\end{array}$ \\
\hline Gestão de TI & $\begin{array}{l}\text { A gestăo de TI pode envolver a análise do cumprimento das } \\
\text { metas de TI e os motivos do seu não cumprimento com vistas à } \\
\text { sua melhoria continua. }\end{array}$ \\
\hline Iniciativas de TI & $\begin{array}{l}\text { As iniciativas de TI devemenvolver a alta administraça com o } \\
\text { objetivo de aprimorar a governança dos riscos de TI. }\end{array}$ \\
\hline Planos de TI & $\begin{array}{l}\text { Os planos de TI devem ser aprovados pela alta administraçăo, } \\
\text { possuir comunicação com os planos de gestão de riscos e } \\
\text { constar das prestações de contas com o fito de garantir a } \\
\text { continuidade do negócio. }\end{array}$ \\
\hline Entrega de valor & $\begin{array}{l}\text { Objetivo da governança de TI alcançado por meio do } \\
\text { atendimento às necessidades das partes interessadas e da } \\
\text { atuação estratégica da TI de responsabilidade da alta } \\
\text { administração e dos comitês de TI. }\end{array}$ \\
\hline Continuidade & $\begin{array}{l}\text { Subgrupo da gestăo de ris cos de TI que env olve a integraçáo de } \\
\text { planos de contingência, cópias de segurança, gerenciamento de } \\
\text { crises, respostas às emergências e recuperação de desastres. }\end{array}$ \\
\hline Efetividade & $\begin{array}{l}\text { Beneficios gerados pelos investimentos de TI traduzidos por } \\
\text { meio de indicadores e metas. }\end{array}$ \\
\hline $\begin{array}{l}\text { Definição de } \\
\text { responsabilidades }\end{array}$ & $\begin{array}{l}\text { A definição de responsabilidades deve considerar a } \\
\text { participação da alta administração nas decisões de TI com } \\
\text { vistas a agregação de valor ao negócio. }\end{array}$ \\
\hline
\end{tabular}

De acordo com Borges-Andrade e Abbad (1996), o treinamento é um esforço organizacional para criar oportunidades de aprendizagem aos colaboradores. O intuito é identificar e suprir as deficiências no desempenho de empregados e adaptá-los às novas funções e tecnologias de trabalho. O SISP tem uma visão mais restrita do tópico como uma capacitação dos quadros de TIC respaldada pelo PDTIC.

Segundo Neely et al. (2000) e Teló (2001), a prestação de contas é uma das ferramentas para a melhoria do desempenho organizacional considerando o alinhamento de objetivos e metas. A semelhança é que o SISP entende prestação de contas como uma avaliação das ações de TIC por meio das metas e decisões organizacionais.

Para Haggerty et al. (2003), a continuidade se traduz na conexão das informações entre as diferentes partes interessadas. O SISP visualiza a continuidade como um subgrupo da 
gestão de riscos de TIC que leva em conta a integração de planos de contingência, cópias de segurança, gerenciamento de crises, respostas às emergências e recuperação de desastres.

Conforme Mintzberg et al. (2000), a responsabilização é um dos valores da cultura organizacional. O SISP entende que a definição de responsabilidades considera a participação da alta administração nas decisões de TIC.

\subsection{DOMÍNIOS, ELEMENTOS, NÍVEIS E PRÁTICAS DO MODELO DE MATURIDADE}

Na elaboração do modelo de maturidade em governança e gestão de TIC para o SISP, consideraram-se os seguintes estágios evolutivos: 0 - Inexistente, 1 - Inicial, 2 - Repetível, 3 - Definida, 4 - Gerenciada e 5 - Otimizada. Segundo Becker et al. (2009) e Tonelli et al. (2017), essas etapas refletem os níveis de progresso do gerenciamento do desempenho da TIC. No nível 0 - Inexistente, ainda não existe uma estrutura formal para a governança e gestão de TIC. No estágio 1 - Inicial; a governança e a gestão de TIC ocorrem de maneira esparsa em alguns departamentos e seções. No nível 2 - Repetível; alguns processos e práticas de governança e gestão de TIC já são repetíveis na instituição. No estágio 3 Definida; a governança e a gestão de TIC já possuem reconhecimento e formalização pela alta administração. Já no nível 4 - Gerenciado, é possível gerenciar, controlar, automatizar e monitorar os processos, procedimentos e práticas de governança e gestão de TIC e os seus impactos nos objetivos organizacionais. Por fim na fase 5 - Otimizada; podem-se melhorar continuamente os elementos de governança e gestão de TIC implantados na instituição.

Com os estágios evolutivos e os conceitos desenvolvidos via Teoria Fundamentada foi elaborada uma estrutura inicial dos domínios e elementos do modelo de maturidade. Os domínios correspondem às categorias Cultura organizacional, Controles internos e Desempenho organizacional oriundas da literatura. Já os elementos correspondem às suas subcategorias consolidadas e refinadas pela Teoria aplicada na documentação do SISP.

Os domínios, elementos e estágios evolutivos permitiram o desenvolvimento das práticas pertinentes ao modelo de maturidade. As práticas foram definidas pelas diretrizes, questões e resultados do modelo conceitual para governança de TIC no setor público proposto por Tonelli et al. (2017) e nos conceitos desenvolvidos através da Teoria Fundamentada aplicada na documentação de governança e gestão de TIC do SISP. 
Por meio da avaliação da capacidade de executar práticas, torna-se possível avaliar o nível de maturidade em governança e gestão de TIC dos órgãos e entidades do SISP. A relação completa das práticas encontra-se nos Quadros 10, 11 e 12.

\subsection{GERAÇÃO DE MODELOS DE MATURIDADE POR MEIO DA ANÁLISE DE CONTEÚDO E DA TEORIA FUNDAMENTADA}

O modelo proposto baseia-se na estrutura apresentada no Quadro 7 contando com as práticas desenvolvidas para cada estágio evolutivo (nível). Os Quadros 10, 11 e 12 apresentam, respectivamente, o modelo detalhado para cada um dos domínios (categorias): Cultura Organizacional, Controles Internos e Desempenho Organizacional.

A estrutura referente ao domínio "Cultura Organizacional" com os respectivos elementos e práticas separados por nível está apresentada no Quadro 10. A cultura organizacional é um sistema de valores compartilhados com diferenças marcantes nos níveis de inovação, estabilidade, resultados, gestão de pessoal e competitividade (ROBBINS, 2012).

O Quadro 11 se refere ao domínio Controles Internos, os elementos e práticas separados por nível. A melhoria dos controles internos deve levar em conta a identificação e a mensuração dos riscos organizacionais (MARTIN et al., 2004).

A apresentação da parte do Modelo referente ao domínio Desempenho Organizacional, seus elementos e práticas, separados por nível, está apresentada no Quadro 12. O desempenho organizacional está associado ao alcance dos resultados, metas e objetivos levando em conta a adequação, eficiência e eficácia (ABBAD, 1999).

Quadro 10. Modelo de maturidade referente ao Domínio “Cultura Organizacional”.

\begin{tabular}{|c|c|c|c|c|c|}
\hline \multicolumn{6}{|c|}{ DOMÍNIO: CULTURA ORGANIZACIONAL } \\
\hline Elementos/nível & Nível 1 - Inicial & \begin{tabular}{|l|} 
Nível 2 - \\
Repetível
\end{tabular} & Nível 3 - Definida & \begin{tabular}{|l|} 
Nível 4 - \\
Gerenciada
\end{tabular} & \begin{tabular}{|l|} 
Nível 5 - \\
Otimizada
\end{tabular} \\
\hline Sensibilização & $\begin{array}{l}\text { C01 - Divulgar na } \\
\text { rede interna } \\
\text { conteúdos sobre } \\
\text { governança e } \\
\text { gestão de TI. }\end{array}$ & $\begin{array}{l}\text { CO2 - Promover, } \\
\text { periodicamente, } \\
\text { eventos sobre } \\
\text { governança e } \\
\text { gestão de TI. }\end{array}$ & $\begin{array}{l}\text { CO3 - Inserir os } \\
\text { temas de } \\
\text { governança e } \\
\text { gestão de TI na } \\
\text { pauta das reuniões } \\
\text { da alta } \\
\text { administração }\end{array}$ & $\begin{array}{l}\text { CO4 - } \\
\text { Acompanhar e } \\
\text { verificar se os } \\
\text { temas de } \\
\text { governança e } \\
\text { gestão de TI são } \\
\text { abordados e } \\
\text { discutidos nas } \\
\text { reuniões da alta } \\
\text { administração. }\end{array}$ & \begin{tabular}{|l} 
CO5 - Identificar \\
quais aspectos dos \\
temas de \\
governança e \\
gestão de TI \\
podem ser \\
abordados com \\
maior \\
profundidade nas \\
reuniões da alta \\
administração \\
\end{tabular} \\
\hline Treinamentos & $\begin{array}{l}\text { C08 - Levantar } \\
\text { com o pessoal de } \\
\text { TI as necessidades }\end{array}$ & $\begin{array}{l}\text { C09 - Promover, } \\
\text { periodicamente, } \\
\text { treinamentos para }\end{array}$ & $\begin{array}{l}\text { C10 - Formalizar } \\
\text { as necessidades de } \\
\text { treinamento do }\end{array}$ & $\begin{array}{l}\text { C11 - Verificar se } \\
\text { as necessidades de } \\
\text { treinamento do }\end{array}$ & $\begin{array}{l}\text { C12 - Identificar e } \\
\text { promover } \\
\text { melhorias no }\end{array}$ \\
\hline
\end{tabular}




\begin{tabular}{|l|l|l|l|l|l|}
\hline & $\begin{array}{l}\text { de treinamentos e } \\
\text { capacitaçôes. }\end{array}$ & o pessoal de TI. & pessoal de TI. & $\begin{array}{l}\text { pessoal de TI são } \\
\text { atendidas. }\end{array}$ & $\begin{array}{l}\text { processo de } \\
\text { treinamento do } \\
\text { pessoal de TI. }\end{array}$ \\
\hline $\begin{array}{l}\text { Prestação de } \\
\text { contas }\end{array}$ & $\begin{array}{l}\text { C13 - Divulgar, } \\
\text { nos setores de TI } \\
\text { as necessidades } \\
\text { dos treinamentos e } \\
\text { capacitações. }\end{array}$ & $\begin{array}{l}\text { C14 - Relacionar } \\
\text { planos, projetos e } \\
\text { serviços de TI com } \\
\text { as metas } \\
\text { organizacionais. }\end{array}$ & $\begin{array}{l}\text { C15 - Formalizar } \\
\text { planos, projetos e } \\
\text { serviços de TI } \\
\text { perante a alta } \\
\text { administração. }\end{array}$ & $\begin{array}{l}\text { C16 - Verificar se } \\
\text { os problemas nos } \\
\text { planos, projetos e } \\
\text { serviços de TI são } \\
\text { de conhecimento } \\
\text { da alta } \\
\text { administração. }\end{array}$ & $\begin{array}{l}\text { C17 } \\
\text { o engajamento da } \\
\text { alta administração } \\
\text { na resolução dos } \\
\text { problemas nos 486 } \\
\text { planos, projetose } \\
\text { serviços de TI. }\end{array}$ \\
\hline
\end{tabular}

Quadro 11. Modelo de maturidade referente ao Domínio "Controles Internos".

\begin{tabular}{|c|c|c|c|c|c|}
\hline \multicolumn{6}{|c|}{ DOMÍNIO: CONTROLES INTERNOS } \\
\hline Elementos/nível & Nível 1 - Inicial & $\begin{array}{l}\text { Nível 2 - } \\
\text { Repetível }\end{array}$ & Nível 3 - Definida & $\begin{array}{l}\text { Nível } 4 \text { - } \\
\text { Gerenciada }\end{array}$ & $\begin{array}{l}\text { Nível } 5 \text { - } \\
\text { Otimizada }\end{array}$ \\
\hline Conformidade & $\begin{array}{l}\text { CI1 - Identificar } \\
\text { formas e práticas } \\
\text { para adequação da } \\
\text { TI às disposições } \\
\text { regulamentares, } \\
\text { legislativas e } \\
\text { contratuais. }\end{array}$ & $\begin{array}{l}\text { CI2 - Promover } \\
\text { reuniões } \\
\text { periódicas com as } \\
\text { seções pertinentes } \\
\text { para atualizar as } \\
\text { áreas de TI quanto } \\
\text { às disposições } \\
\text { regulamentares, } \\
\text { legislativas e } \\
\text { contratuais. }\end{array}$ & $\begin{array}{l}\text { CI3 - Incluir as } \\
\text { áreas de TI nas } \\
\text { reuniões sobre } \\
\text { conformidade às } \\
\text { disposições } \\
\text { regulamentares, } \\
\text { legislativas e } \\
\text { contratuais. }\end{array}$ & $\begin{array}{l}\text { CI4 - Identificar e } \\
\text { remover } \\
\text { obstáculos quanto } \\
\text { à participação das } \\
\text { áreas de TI nas } \\
\text { reuniões sobre } \\
\text { conformidade. }\end{array}$ & $\begin{array}{l}\text { CI5 - Engajar as } \\
\text { áreas de TI sobre a } \\
\text { relevância das } \\
\text { reuniões e boas } \\
\text { práticas de } \\
\text { conformidade. }\end{array}$ \\
\hline Gestão de Riscos & $\begin{array}{l}\text { CI6 - Divulgar na } \\
\text { rede interna } \\
\text { conteúdos sobre } \\
\text { gestão de riscos. }\end{array}$ & \begin{tabular}{|l|} 
CI7 - Promover \\
periodicamente \\
eventos sobre \\
governança de \\
gestão de riscos.
\end{tabular} & $\begin{array}{l}\text { CI8 - Inserir o } \\
\text { tema gestão de } \\
\text { riscos na pauta das } \\
\text { reuniões da alta } \\
\text { administração. }\end{array}$ & $\begin{array}{l}\text { CI9 - } \\
\text { Acompanhar e } \\
\text { verificar se o tema } \\
\text { gestão de riscos é } \\
\text { abordado e } \\
\text { discutido nas } \\
\text { reuniões da alta } \\
\text { administração. }\end{array}$ & $\begin{array}{l}\text { CI10 - Identificar } \\
\text { quais aspectos do } \\
\text { tema gestão de } \\
\text { riscos pode ser } \\
\text { abordado com } \\
\text { mais profundidade } \\
\text { nas reuniões da } \\
\text { alta administração. }\end{array}$ \\
\hline Riscos de TI & $\begin{array}{l}\text { CI11 - Levantar } \\
\text { os riscos de TI nos } \\
\text { processos } \\
\text { finalísticos, de } \\
\text { apoio e gerenciais. }\end{array}$ & $\begin{array}{l}\text { CI12 - Divulgar } \\
\text { em toda a } \\
\text { organização os } \\
\text { riscos de TI } \\
\text { levantados. }\end{array}$ & \begin{tabular}{|l|} 
C113 - Priorizar \\
junto à alta \\
administração os \\
riscos de TI a \\
serem tratados.
\end{tabular} & $\begin{array}{l}\text { CI14 - Promover } \\
\text { o tratamento dos } \\
\text { riscos de TI } \\
\text { priorizados. }\end{array}$ & $\begin{array}{l}\text { CI15 - Identificar } \\
\text { e remover } \\
\text { obstáculos no } \\
\text { tratamento dos } \\
\text { riscos de TI. }\end{array}$ \\
\hline Gestão de TI & $\begin{array}{l}\text { CI16 - Identificar } \\
\text { as metas das áreas } \\
\text { de TI. }\end{array}$ & $\begin{array}{l}\text { CI17 - Divulgar } \\
\text { em toda a } \\
\text { organização as } \\
\text { metas das áreas de } \\
\text { TI. }\end{array}$ & $\begin{array}{l}\text { CI18 - Alinhar as } \\
\text { metas das áreas de } \\
\text { TI às metas da alta } \\
\text { administração. }\end{array}$ & $\begin{array}{l}\text { CI19 - Priorizar a } \\
\text { execução das } \\
\text { metas das áreas de } \\
\text { TI. }\end{array}$ & $\begin{array}{l}\text { CI20 - Identificar } \\
\text { e remover } \\
\text { obstáculos no } \\
\text { alcance das metas } \\
\text { de TI. }\end{array}$ \\
\hline Serviços de TI & $\begin{array}{l}\text { CI21 - Elaborar } \\
\text { metas de nível de } \\
\text { serviço para os } \\
\text { serviços de TI. }\end{array}$ & $\begin{array}{l}\text { CI22 - Divulgar } \\
\text { nas áreas de TI as } \\
\text { metas de nível de } \\
\text { serviço. }\end{array}$ & $\begin{array}{l}\text { CI23 - Promover } \\
\text { gestões para que } \\
\text { as metas de nível } \\
\text { de serviço } \\
\text { cheguem ao } \\
\text { conhecimento da } \\
\text { alta administração. }\end{array}$ & $\begin{array}{l}\text { CI24 - Priorizar } \\
\text { junto à alta } \\
\text { administração a } \\
\text { realização das } \\
\text { metas de nível de } \\
\text { serviço. }\end{array}$ & $\begin{array}{l}\text { CI25 - Identificar } \\
\text { e promover } \\
\text { melhorias nas } \\
\text { metas de nível de } \\
\text { serviço. }\end{array}$ \\
\hline Iniciativas de TI & $\begin{array}{l}\text { CI26 - Levantar } \\
\text { iniciativas de TI } \\
\text { relevantes para as } \\
\text { áreas de TI. }\end{array}$ & $\begin{array}{l}\text { CI27 - Divulgar } \\
\text { em toda a } \\
\text { organização as } \\
\text { iniciativas de TI. }\end{array}$ & $\begin{array}{l}\text { CI28 - Priorizar } \\
\text { junto à alta } \\
\text { administração a } \\
\text { execução das } \\
\text { iniciativas de TI. }\end{array}$ & $\begin{array}{l}\text { CI29-Gerenciar } \\
\text { a execução das } \\
\text { iniciativas de TI } \\
\text { priorizadas. }\end{array}$ & $\begin{array}{l}\text { CI30 - Identificar } \\
\text { e promover } \\
\text { melhorias na } \\
\text { execução das } \\
\text { iniciativas de TI. }\end{array}$ \\
\hline
\end{tabular}




\begin{tabular}{|l|l|l|l|l|l|}
\hline & & & & \\
\hline Planos de TI & $\begin{array}{l}\text { CI31 - Planejar as } \\
\text { ações de TI. }\end{array}$ & $\begin{array}{l}\text { CI32 - Divulgar } \\
\text { os planos da TI na } \\
\text { organização. }\end{array}$ & $\begin{array}{l}\text { CI33 - Alinhar os } \\
\text { planos de TI com } \\
\text { os planos da alta } \\
\text { administração. }\end{array}$ & $\begin{array}{l}\text { CI34 - Gerenciar } \\
\text { a execução dos } \\
\text { planos de TI. }\end{array}$ & $\begin{array}{l}\text { CI35 - Identificar } \\
\text { e promover } \\
\text { melhorias na } \\
\text { execução dos } \\
\text { planos de TI. }\end{array}$ \\
\hline
\end{tabular}

Quadro 12. Modelo de maturidade referente ao Domínio "Desempenho Organizacional”.

\begin{tabular}{|c|c|c|c|c|c|}
\hline \multicolumn{6}{|c|}{ DOMÍNIO: DESEMPENHO ORGANIZACIONAL } \\
\hline Elementos/nível & Nível 1 - Inicial & \begin{tabular}{|l|} 
Nível 2 - \\
Repetível
\end{tabular} & \begin{tabular}{|l|} 
Nível 3 - \\
Definida \\
\end{tabular} & \begin{tabular}{|l|} 
Nível 4 - \\
Gerenciada \\
\end{tabular} & \begin{tabular}{|l|} 
Nível 5 - \\
Otimizada \\
\end{tabular} \\
\hline Entrega de Valor & $\begin{array}{l}\text { DO1 - Levantar as } \\
\text { necessidades das } \\
\text { partes interessadas } \\
\text { da organização. }\end{array}$ & $\begin{array}{l}\text { DO2 - Divulgar as } \\
\text { necessidades das } \\
\text { partes interessadas } \\
\text { nas áreas de TI. }\end{array}$ & $\begin{array}{l}\text { DO3 - Priorizar } \\
\text { junto à alta } \\
\text { administração as } \\
\text { necessidades das } \\
\text { partes } \\
\text { interessadas. }\end{array}$ & $\begin{array}{l}\text { DO4 - Direcionar } \\
\text { os esforços das } \\
\text { áreas de TI para o } \\
\text { atendimento das } \\
\text { necessidades das } \\
\text { partes interessadas. }\end{array}$ & $\begin{array}{l}\text { DO5 - Identificar } \\
\text { e remover } \\
\text { obstáculos para } \\
\text { que as áreas da TI } \\
\text { atendam às } \\
\text { necessidades das } \\
\text { partes } \\
\text { interessadas. }\end{array}$ \\
\hline Con & $\begin{array}{l}\text { DO6 - Identificar } \\
\text { e mapear com as } \\
\text { áreas de TI planos } \\
\text { de contingência e } \\
\text { procedimentos de } \\
\text { segurança. }\end{array}$ & $\begin{array}{l}\text { DO7 - Identificar } \\
\text { e mensurar os } \\
\text { impactos da } \\
\text { descontinuidade } \\
\text { dos serviços de TI } \\
\text { nas áreas da } \\
\text { organização. }\end{array}$ & \begin{tabular}{|l|} 
DO8 - Obter \\
apoio da alta \\
administração \\
para melhorar os \\
planos de \\
contingência e \\
procedimentos de \\
segurança.
\end{tabular} & $\begin{array}{l}\text { DO9 - Gerenciar a } \\
\text { execução dos } \\
\text { planos de } \\
\text { contingência e } \\
\text { procedimentos de } \\
\text { segurança. }\end{array}$ & $\begin{array}{l}\text { DO10 - Identificar } \\
\text { e resolver } \\
\text { problemas na } \\
\text { execução dos } \\
\text { planos de } \\
\text { contingência e } \\
\text { procedimentos de } \\
\text { segurança. }\end{array}$ \\
\hline Efet & $\begin{array}{l}\text { DO11 - Identificar } \\
\text { indicadores } \\
\text { pertinentes às } \\
\text { áreas de TI. }\end{array}$ & $\begin{array}{l}\text { DO12-Divulgar } \\
\text { os indicadores de } \\
\text { TI perante a } \\
\text { organização. }\end{array}$ & \begin{tabular}{|l|} 
DO13 - Incluir \\
os indicadores de \\
TI nos planos da \\
alta \\
administração. \\
\end{tabular} & $\begin{array}{l}\text { DO14 - Gerenciar } \\
\text { a coleta de } \\
\text { informações para os } \\
\text { indicadores de TI. }\end{array}$ & $\begin{array}{l}\text { DO15 - Propor } \\
\text { ações corretivas } \\
\text { conforme os } \\
\text { resultados dos } \\
\text { indicadores. } \\
\end{array}$ \\
\hline $\begin{array}{l}\text { Definição de } \\
\text { Responsabilidade } \\
\text { S }\end{array}$ & $\begin{array}{l}\text { DO16 - Elencar as } \\
\text { principais } \\
\text { responsabilidades } \\
\text { da governança e } \\
\text { gestão de TI. }\end{array}$ & $\begin{array}{l}\text { DO17 - Divulgar } \\
\text { as } \\
\text { responsabilidades } \\
\text { da governança e } \\
\text { gestão de TI } \\
\text { perante a } \\
\text { organização. }\end{array}$ & \begin{tabular}{|l|} 
DO18 - \\
Formalizar as \\
responsabilidades \\
da governança e \\
gestão de TI com \\
a alta \\
administração.
\end{tabular} & $\begin{array}{l}\text { DO19 - } \\
\text { Compatibilizar as } \\
\text { responsabilidades } \\
\text { pela governança e } \\
\text { gestão de TI com as } \\
\text { responsabilidades } \\
\text { da alta } \\
\text { administração. } \\
\end{array}$ & $\begin{array}{l}\text { DO20 - Identificar } \\
\text { e resolver } \\
\text { problemas quanto } \\
\text { à execução das } \\
\text { responsabilidades } \\
\text { da governança e } \\
\text { gestão de TI. }\end{array}$ \\
\hline
\end{tabular}

Vale considerar a seguinte análise, para avaliar o nível de maturidade da organização do domínio Desempenho Organizacional (DO) no elemento "Entrega de valor", é necessário identificar qual prática dentre as DO01, DO02, DO03, DO04 e DO5 já é realizada ou possui condições de ser realizada. Caso a instituição já execute a prática DO04, então o seu nível de maturidade será 4 - Gerenciado. O mesmo raciocínio se aplica para todas as práticas dos outros domínios nos seus respectivos elementos.

É interessante uma análise supondo que a organização alcançou os níveis $0,2,3$ e 5 nos elementos do domínio - Desempenho organizacional. Então, para esse domínio, o nível de 
maturidade será 0 - Inexistente, pois se considera a menor nota obtida nas avaliações. $\mathrm{O}$ intuito é estimular que as instituições do SISP aprimorem os seus elementos de governança e gestão de TIC como um todo e não apenas em áreas e aspectos específicos. Essa mesma lógica se aplica também aos demais domínios.

Depois de aplicadas as avaliações em todos os domínios, então, considera-se também a menor obtida nessas avaliações e essa corresponderá ao nível de maturidade em governança e gestão de TIC da organização do SISP avaliada. Considere, por exemplo, os níveis 1, 3 e 5 para os domínios: Cultura organizacional, Controles internos e Desempenho organizacional. Então o nível de maturidade da instituição avaliada será 1 - Inicial.

Costa Filho e Rosa (2017) enfatizam que a maturidade exige modelos sistematizados por meio da avaliação das boas práticas das organizações. As demandas da governança e gestão de TIC são complexas e vão além do alcance dos modelos de maturidade com passos sequenciais. Tais modelos não são soluções prontas para uso pelas instituições. É necessário antes alinhar a cultura organizacional, capital humano e prioridades das partes interessadas para que os modelos de maturidade criem valor para o negócio. Embora os modelos de maturidade sejam objetivos e estáticos, estes podem servir como ponto de partida para visualizar a complexidade da governança pública.

Convém mencionar que a documentação do SISP possui em parte uma intersecção com os critérios de maturidade elencados na literatura. Por meio da aplicação da Teoria Fundamentada, observou-se que a referida documentação contempla muito mais questões sobre gestão de TIC do que sobre governança. A título de exemplo, pode-se citar o surgimento das categorias codificadas: Prestações de contas, Gestão de TIC, Serviços de TIC, Iniciativas de TIC e Planos de TIC. Ilustra-se também que a Análise de Conteúdo possui uma abrangência maior do que a da Teoria Fundamentada e que ambas se utilizam da classificação e da categorização de unidades de registro para uma melhor organização das informações documentadas.

\section{DISCUSSÃO DOS RESULTADOS}

Calcado na literatura e nas documentações do SISP, sugerem-se boas práticas para o aprimoramento dos controles internos e do desempenho das entidades públicas no escopo da TIC. Pode-se aplicar a metodologia desenvolvida a outros temas distintos da governança e gestão de TIC visto que a análise de conteúdo junto com a teoria fundamentada permitiu a 
geração de categorizações de termos da literatura e o posterior desenvolvimento de conceitos baseados puramente nas documentações de referência. Trata-se de um modelo de maturidade destinado ao SISP e, com isso, possui um escopo limitado e restrito aos cenários e particularidades do Poder Executivo do Governo Federal Brasileiro.

Além disso, observou-se que o arcabouço conceitual abordado pelo SISP considera, em alguns casos, uma limitação de abrangência se relacionada com as definições da literatura. Tal limitação conceitual são desafios que dificultam o alcance de uma implementação da governança sob a perspectiva ampla que seu constructo representa. Ao comparar os constructos do SISP e da literatura, observou-se que ambas abordam questões sobre sensibilização organizacional, responsabilização, entrega de valor, gestão de riscos, boas práticas de TIC e conformidade. Percebe-se um foco maior do SISP nos riscos, iniciativas, planos e gestão de TIC. Entretanto, o SISP não explora com profundidade os temas atinentes às lideranças, processos de governança de TIC, estruturas decisórias e medição do desempenho da TIC.

A maturidade em governança e gestão de TIC contribui para a eficácia dos investimentos tecnológicos e atua como facilitadora do alcance dos objetivos de uma organização. Porém, Bueno et al. (2018) ressalva que as boas práticas de governança corporativa ainda são fracas no cenário brasileiro. Trabalhos posteriores poderiam explorar, por exemplo, a maturidade em governança e gestão de TIC no judiciário, nos Estados, no Sistema $\mathrm{S}$ ou nas empresas estatais. Podem-se abordar também as dificuldades das instituições públicas para se adequarem às boas práticas do mercado. No que se refere a medidas para contrabalançar tais dificuldades no caso da governança de empresas estatais, cabe notar o artigo de Canedo et al. (2018), acerca de kits de melhores práticas para o processo de governança de TIC dessas empresas em sua relação com a Secretaria de Empresas Estatais, do então Ministério do Planejamento, Orçamento e Gestão, hoje Ministério da Economia.

A publicação de Santos e Souza Neto (2013) é um modelo de maturidade em governança de TIC para os órgãos da APF baseado nas normativas da ISO sobre governança. Todavia, o modelo de governança e gestão de TIC deste trabalho é de 2019 e possui conceitos construídos via Teoria Fundamentada que divergem dos conteúdos trazidos à tona por Santos e Souza Neto (2013). Diante dessa defasagem temporal e das diferenças conceituais, sugerese como trabalhos futuros uma revisão dos termos das normas ISO sobre governança de TIC. 
Sugerem-se também estudos futuros para analisar e comprovar se os critérios de governança de TIC do meio acadêmico possuem relação com os critérios de governança e gestão de TIC do SISP. As justificativas para esse trabalho se respaldam na materialidade do controle e destinação das verbas públicas aplicadas em tecnologia, na complexidade de se desenvolver sistemas informatizados alinhados aos objetivos estratégicos e nas dificuldades para mudanças nas culturas organizacionais. A quantidade limitada de publicações sobre o tema também contribui para a relevância desta pesquisa. Fabriz et al. (2018) constata que há uma preocupação crescente sobre como monitorar os benefícios das TIC utilizadas pelo governo brasileiro e a necessidade de mudança cultural para que os serviços prestados sejam de fato eficientes.

\section{CONSIDERAÇÕES FINAIS}

Pode se concluir que a maturidade em governança e gestão de TIC envolve mudanças no desempenho, na cultura organizacional e nos controles internos. Para tanto, pode-se promover treinamentos e sensibilização, discutir sobre conformidade e gestão de riscos, alinhar iniciativas, planos e serviços de TI, definir responsabilidades e internalizar conceitos de efetividade, entrega de valor e continuidade. O modelo de maturidade em governança e gestão de TIC concebido neste trabalho é uma continuidade às pesquisas de Xavier (2010) e de Santos e Souza Neto (2013) que avaliaram a maturidade e a capacidade da governança de TIC na Administração Direta Federal. Além disso, o emprego da Teoria Fundamentada permitiu desenvolver conceitos pertinentes à governança e gestão de TIC totalmente baseados nas documentações do SISP. Trata-se de um modelo com conceituações puras, sem premissas e sem vieses pessoais. Como um comparativo entre as documentações do SISP e os critérios de maturidade da literatura, percebeu-se que ambos tratavam dos conceitos sobre: Sensibilização, Conformidade, Gestão de riscos, Planos de TIC, Entrega de valor e Definição de responsabilidades. Observou-se, porém, que o SISP não possui conceituações acerca dos termos Estruturas de tomada de decisão, Comitês de TIC, Lideranças, Políticas, Alinhamento estratégico e Processos de governança de TIC.

\section{REFERÊNCIAS}


ABBAD, G. Um modelo integrado de avaliação do impacto do treinamento no trabalho. Tese- Instituto de Psicologia da Universidade de Brasília, Brasília, Distrito Federal, Brasil, 1999.

ABU KHADRA, H., ZURIEKAT, M., \& ALRAMAHI, N. An empirical examination of maturity model as measurement of information technology governance implementation. International Arab Journal of Information Technology, 6(3), 310-319, 2009.

AL OMARI, L. It governance evaluation: Adapting and adopting the COBIT framework for public sector organizations. PhD thesis, Queensland University of Technology, 2016.

ALMEIDA NETO, H. R., MAGALHÃES, E. M. C, Moura, H. P. Avaliação de um Modelo de Maturidade para Governança Ágil em Tecnologia da Informação e Comunicação. iSys Revista Brasileira de Sistemas de Informação, Rio de Janeiro, 8 (4), 44-79, 2015.

BARDIN, L. L'Analyse de contenu. Editora: Presses Universitaires de France, 1977.

BARDIN, L. Análise de Conteúdo. Almedina: Ed. São Paulo, 2011.

BAINES, Tim; LIGHTFOOT, Howard. Servitization of the manufacturing firm: Exploring the operations practices and technologies that deliver advanced services. International Journal of Operations \& Production Management, vol. 34, ed. 1, p. 2-35, 2013.

BECKER, J., KNACKSTEDT, R., \& PÖPPELBUB, J. Developing Maturity Models for IT Management - A Procedure Model and its Application. Business \& Information Systems Engineering (BISE), 1(3), 213-222, 2009.

BORGES-ANDRADE, J. E., \& ABBAD G. Treinamento no Brasil: reflexões sobre suas pesquisas. Revista de Administração, 31(2), 112-125, 1996.

BUENO, G.; NASCIMENTO, K; LANA, J.; GAMA, M. A. B., \& MARCON, R. Mecanismos Externos de Governança Corporativa no Brasil. Revista Contabilidade, Gestão e Governança, 21(1), 120-141. http://dx.doi.org/10.21714/1984-3925_2018v21n1a7, 2018.

BUTZKE, I.C; PEREIRA, G.R.; NOEBAUER, D. Sugestão de indicadores para avaliação do desempenho das atividades educativas do sistema de gestão ambiental. SGA da Universidade Regional de Blumenau, FURB, 2007.

CANEDO, E., COSTA, R., SOUSA JUNIOR., R. T., \& AMVAME-NZE, G. Best Practices Kits for the ICT Governance Process within the Secretariat of State-Owned Companies of Brazil and Regarding these Public Companies. Information (Switzerland), 9(6), 141, 2018.

COBO, A., VANTI, A. A., \& ROCHA, R. (2014). A fuzzy multicriteria approach for it governance evaluation. JISTEM - Journal of Information Systems and Technology Management, 11(2), 257-276, 2014.

COSTA FILHO, Bento Alves; ROSA, Fernando de. Maturidade em Gestão Ambiental: Revisitando as Melhores Práticas REAd. Revista Eletrônica de Administração. (Porto Alegre), Porto Alegre, v. 23, n. 2, p. 110-134, ago. 2017.

DE BRUIN, T., FREEZE, R., KAULKARNI, U., ROSEMANN, M. Understanding the main phases of developing a maturity assessment model. In: Australas. Conference Information Systems., pp. 8e19., 2005. 
DE HAES, S., \& VAN GREMBERGEN, W. An Exploratory Study into IT Governance implementation and its impacts on business/IT alignment. Information Systems Management, 26(2), 123-137, 2009.

DE PAIVA GONÇALVES, A., ANTÔNIO GASPAR, M., \& CARDOSO, M. (2016). Governança de Tecnologia da Informação: Uma Análise do Nível de Maturidade em Empresas Atuantes no Brasil. Revista de Gestão e Projetos, 7(1), 56-69, 2016.

DEMIR, F. Measuring Strategic Management Maturity: An Empirical Study in Turkish Public and Private Sector Organizations. World Academy of Science, Engineering and Technology International Journal of Economics and Management Engineering, 11(11): 2433-2440, 2017.

FABRIZ, S. M., GOMES, A. R. V.; \& MELLO, G. R. Governança Eletrônica: Uma Análise Bibliométrica dos Periódicos Nacionais e Internacionais. Revista Contabilidade, Gestão e Governança, 21(3), 320-338, 2018.

FERNANDES, B.H.; FLEURY, M.T.; MILLS, J. Construindo o diálogo entre competência, recursos e desempenho organizacional. Revista de Administração de Empresas (RAE), São Paulo, v.46, n.4, p.48-65, out./dez. 2006.

FRAGOSO, S., RECUERO, R., \& AMARAL, A. Métodos de pesquisa para internet. Porto Alegre: Sulina, 2011.

GASQUE, K. C. G. D. Teoria Fundamentada: nova perspectiva à pesquisa exploratória. In: Métodos para a pesquisa em Ciências da Informação. Brasília: Thesaurus, p. 107-142, 2007.

HAGGERTY J. L, REID R. J, FREEMAN G. K, STARFIELD B. H, ADAIR C. E, MCKENDRY R. Continuity of care: a multidisciplinary review. BMJ; 22; 327(7425): 1219$1221,2003$.

INTRONA, V., CESAROTTI, V., BENEDETTI, M., BIAGIOTTI, S., ROTUNNO, R. Energy Management Maturity Model: an organizational tool to foster the continuous reduction of energy consumption in companies. Journal Clean. Prod. 83, 108e117. Elsevier Ltd, 2014.

KO, D., \& FINK, D. Information technology governance: an evaluation of the theory- practice gap. Corporate Governance: The international journal of business in society, 10 (5), 662-674, 2010.

LUCIANO, E.; MACADAR, M. Governança de TIC em Organizações Públicas. In: Alexandre F. Barbosa. (Org.). TIC Governo Eletrônico. São Paulo, SP: Comitê Gestor da Internet no Brasil - CGI.br, 2016, p. 55-63, 2015.

LUNARDI, G.; BECKER, J.; MAÇADA, A.; DOLCI, P. The impact of adopting IT Governance on financial performance: An empirical analysis among Brazilian firms. International Journal of Accounting Information Systems, vol. 15, ed. 1, p. 66-81, 2014.

MACHADO PADILHA, A. C., SEVERO, L. S., DELGADO, N. D. A., \& Silva, T. N. Inovação tecnológica em indústrias competitivas do agronegócio: uma análise na Cooperativa Vinícola Aurora Ltda.- RS. Estudo \& Debate,17(1), 91-109, 2010. 
MARTIN, N.C.; SANTOS, L.R.; DIAS FILHO, J.M. Governança Empresarial, Riscos e Controles Internos: A Emergência de um Novo Modelo de Controladoria. Revista

Contabilidade \& Finanças - USP, São Paulo, n. 34, p. 7-22, janeiro/abril 2004.

MINTZBERG, H. Safari de estratégia: um roteiro pela selva do planejamento estratégico.

Porto Alegre: Bookman, 2000.

MPDG. Portal do SISP. 2011. Recuperado em 15 de julho de 2017, de <http://www.sisp.gov.br/faq_sisp/one-faq?faq_id=13929432>

NEELY, A., MILLS, J., \& PLATTS, K. Performance measurement system design: developing and testing a process-based approach. International Journal of Operations \& Production Management, 20(10), 1119-1145, 2000.

NETO, J. S., \& NETO, A. N. F. Metamodel of the IT governance framework COBIT. JISTEM - Journal of Information Systems and Technology Management, 10(3), 521-540, 2013.

OLIVEIRA, A. Modelos de maturidade: visão geral. Curitiba, Mundo PM, n.6, p. 6-11, 2006.

OLIVEIRA, L. M., PEREZ JUNIOR, J. H., \& Silva, C. A. S.. Controladoria estratégica. São Paulo: Atlas, 2009.

REIS, A. L. N. Fatores críticos de sucesso na implantação da governança da tecnologia da informação na Administração Pública Federal. Dissertação de Mestrado, Universidade Católica de Brasília, Brasília, DF, Brasil, 2016.

ROBBINS, Stephen P.; SOBRAL, Filipe. Comportamento organizacional. 14. ed. São Paulo: Prentice-Halll, 2012.

RODRIGUES, J. G. L. Diretrizes para implantação da Governança de TI no setor público brasileiro à luz da Teoria Institucional. Dissertação de Mestrado, Universidade Católica de Brasília, Brasília, DF, Brasil, 2010.

SANTOS, D. L. N., \& SOUZA NETO, J. Avaliação da capacidade dos processos de governança corporativa de TIC baseada no COBIT 5. Dissertação de Mestrado, Universidade Católica de Brasília, Brasília, DF, Brasil, 2013.

SILVA, L. M., \& SOUZA NETO, J. Method for Measuring the Alignment between Information Technology Strategic Planning and Actions of Information Technology Governance. JISTEM - Journal of Information Systems and Technology Management, 11(1), 131-152, 2014.

SISP. RT Levantamento Realizado Junto aos Órgãos do SISP, 2015. Recuperado em 7 de setembro de 2017, de <http://sisp.gov.br/govtic/wiki/download/file/Levantamento_Completo>.

SISP. Quadro de Referência para Governança de TIC. (2016). Recuperado em 7 de agosto de 2017, de <http://sisp.gov.br/wikisisp/wiki/quadro_de_referencia_govti>

STRAUSS, A.; CORBIN, J. Metodologia da Teoria Fundamentada. 1997. 
TELÓ, A. R. Desempenho organizacional: planejamento financeiro em empresas familiares. Revista FAE, 4(1), 17- 26, 2001.

TONELLI, A., BERMEJO, P. S., SANTOS, P., ZUPPO, L., \& ZAMBALDE, A. (2015). IT governance in the public sector: a conceptual model. Information Systems Frontiers, 19(3), 593-610, 2015.

TCU. Referencial básico de governança aplicável a órgãos e entidades da administração pública. Brasília: TCU, Secretaria de Planejamento, Governança e Gestão, 2014.

TCU. Levantamento de governança de TIC 2014. Brasília: TCU, Secretaria de Fiscalização de Tecnologia da Informação, 2015.

TCU. Levantamento de governança de TIC 2016. Brasília: TCU, Secretaria de Fiscalização de Tecnologia da Informação, 2016.

VELASQUEZ PEREZ, T., PUENTES VELASQUEZ, A. M., \& PEREZ PEREZ, Y. M. (2015). Un enfoque de buenas prácticas de gobierno corporativo de TIC, Tecnura [online], 19, 159-169, 2015.

WEILL, Peter; ROSS, W. Jeanne. Governança de TI: como as empresas com melhor desempenho administram os direitos decisórios de TI na busca por resultados superiores. São Paulo: Makron Books, 2006.

WENDLER, R.. The maturity of maturity model research: a systematic mapping study. Inf. Softw. Technol. 54 (12), 1317e1339, 2012.

WU, S. P., STRAUB, D. W., \& LIANG, T. P. How information technology governance mechanisms and strategic alignment influence organizational performance: insights from a matched survey of business and it managers. MIS Quarterly, 39(2), 497-518, 2015.

XAVIER, M. B. G. Mensuração da maturidade da governança de TIC na administração direta federal brasileira. Dissertação de Mestrado, Universidade Católica de Brasília, Brasília, DF, Brasil, 2010. 